Check for updates

Cite this: J. Mater. Chem. C, 2017, 5, 9638

\section{Blue-emitting cationic iridium(III) complexes featuring pyridylpyrimidine ligands and their use in sky-blue electroluminescent devicest:}

\author{
Adam F. Henwood, (D) amlan K. Pal, ${ }^{a}$ David B. Cordes, (D) a \\ Alexandra M. Z. Slawin, (D) ${ }^{a}$ Thomas W. Rees, ${ }^{b}$ Cristina Momblona, ${ }^{c}$ Azin Babaei, \\ Antonio Pertegás, ${ }^{c}$ Enrique Ortí, (D) ${ }^{c}$ Henk J. Bolink, (DD ${ }^{*}$ Etienne Baranoff*b and \\ Eli Zysman-Colman (D) *a
}

\begin{abstract}
The synthesis and structural and photophysical characterisation of four novel, cationic iridium(III) complexes are reported. These complexes were designed to emit in the blue region of the visible spectrum without employing $\mathrm{sp}^{2}$ carbon-fluorine bonds, which have been shown to be electrochemically unstable. Two different $C^{\wedge} N$ (where $C^{\wedge} N$ is a bidentate cyclometalating ligand possessing a nitrogen-carbon chelate) ligands [5-(4-methylpyridin-2-yl)-2,4-dimethoxypyrimidine (Mepypyrm) and 5-(5-(trifluoromethyl)pyridine2-yl)-2,4-dimethoxypyrimidine ( $\mathrm{CF}_{3}$ pypyrm)] combine electron-withdrawing pyrimidyl nitrogen atoms (in a para relationship with respect to the metal) with methoxy groups in a meta relationship with respect to the metal, which both inductively withdraw electron density from the metal centre, stabilizing the highest occupied molecular orbital. The result is highly efficient $\left(\Phi_{\mathrm{PL}}=73-81 \%\right)$ green to blue $\left(\lambda_{\mathrm{PL}}=446-515 \mathrm{~nm}\right)$ emission for complexes 1-4 in MeCN solution. Complex 1 exhibits a broad, unstructured charge transfer (CT) emission profile, while complexes 2-4 exhibit structured, vibronic emission profiles. Density Functional Theory (DFT) calculations corroborate these findings with spin density calculations predicting a $T_{1}$ state that is metal-to-ligand and ligand-to-ligand $\left(C^{\wedge} N\right.$ to $\left.N^{\wedge} N\right)$ charge transfer $\left({ }^{3} M L C T /{ }^{3} L L C T\right)$ in nature for complex 1, while complexes 2-4 are predicted to exhibit ligand-centred $\left({ }^{3} L C\right)$ states with spin density localised exclusively on the $C^{\wedge} N$ ligands. These complexes were used as emitters in sky-blue and bluegreen light-emitting electrochemical cells (LEECs). The bluest of these devices (CIE: 0.23, 0.39) is among the bluest reported for any iridium-based LEEC. It is noteworthy that although the electroluminescence intensity decreases rapidly with time $\left(t_{1 / 2}=0.1-20 \mathrm{~min}\right)$, as is typical of blue-green LEECs, for devices L1, L3 and L4 we have observed for the first time that this decay occurs without an accompanying red-shift in the $\mathrm{CIE}$ coordinates over time, implying that the emitter does not undergo any chemical degradation process in the non-doped zones of the device.
\end{abstract}

rsc.li/materials-c

\section{Introduction}

Light-emitting electrochemical cells (LEECs) are simple solidstate lighting devices composed of only one or two organic layers sandwiched between two electrodes. ${ }^{1}$ The emissive layer is composed of charged compounds that are typically either a conjugated fluorescent polymer with an ionic salt additive, ${ }^{1 b, 2}$ or a phosphorescent ionic transition metal complex (iTMC), ${ }^{3}$ although more recently quantum $\operatorname{dot}^{4}$ and perovskite ${ }^{5}$ based devices have emerged as well. The iTMCs have been the most widely studied class of emissive materials as the phosphorescent nature of the emitter enables all the excitons generated in the device to be converted into light. Among iTMCs, iridium(III) complexes of the form $\left[\operatorname{Ir}\left(\mathrm{C}^{\wedge} \mathrm{N}\right)_{2}\left(\mathrm{~N}^{\wedge} \mathrm{N}\right)\right]^{+}$(where $\mathrm{C}^{\wedge} \mathrm{N}$ is a bidentate cyclometalating ligand such as 2-phenylpyridinato, 
ppy, and $\mathrm{N}^{\wedge} \mathrm{N}$ is a bidentate diimine ligand such as $2,2^{\prime}$-bipyridine, bpy) are the most popular, due to their short phosphorescence lifetimes, wide range of accessible colours, high photoluminescence quantum yields and high photo- and chemostabilities. ${ }^{3 a, b}$

Upon application of an external bias to the LEEC there is a redistribution of ions in the emissive layer, lowering the barrier to charge injection and facilitating light emission. ${ }^{6}$ The smaller charge injection barrier thereby permits the use of air-stable electrodes to operate the LEEC while the charged nature of the emissive layer mitigates the need for additional charge transport layers that are normally required for conventional organic lightemitting devices (OLEDs). Thus, these devices are structurally simple and can be fabricated using solution-processing techniques onto a variety of substrates, making them an attractive cost-effective technology for large area displays and lighting..$^{1 b, 7}$

For all the potential of LEECs, the biggest limiting factors impeding their widespread adoption so far are: (1) their inferior stability compared to OLEDs and (2) the near complete absence of blue emitters. So far, the bluest iTMC LEEC reported, ${ }^{8}$ as determined by the device's Commission Internationale de l'Éclairage (CIE) $x, y$ coordinates (CIE: 0.20, 0.28), does not come close to the ideal blue CIE coordinates (CIE: 0.14, 0.08) ${ }^{9}$ and shows poor external quantum efficiency $(\mathrm{EQE}=0.28 \%)$. Higher device efficiencies (EQE $=3.4-7.6 \%$ ) have been reported, but these values are limited to blue-green devices with significantly red-shifted CIE $y$ coordinates $\left(\mathrm{CIE}_{x}=0.20-0.25 ; \mathrm{CIE}_{y}=\right.$ $0.40-0.46$ ), which means that they cannot be considered as 'true-blue' devices. ${ }^{10}$ Among the devices reported with electroluminescence maxima less than $500 \mathrm{~nm}$, the longest device lifetime reported is only $2.17 \mathrm{~h}^{.11}$

One of the most common strategies for blue-shifting the emission of cationic iridium complexes is to modify the cyclometalating ring of the $\mathrm{C}^{\wedge} \mathrm{N}$ ligands with electron-withdrawing fluorine atoms [making ligands like 2-(2,4-difluorophenyl)pyridine, $\mathrm{dFppy}^{12}$ ] that stabilise the HOMO orbitals localised on the phenyl ring and the metal atom. However, it has been demonstrated that the $\mathrm{C}_{\text {aryl }}-\mathrm{F}$ bonds on the $\mathrm{C}^{\wedge} \mathrm{N}$ ligands are inherently unstable in the device, with defluorination a known degradation pathway in both LEECs and OLEDs. ${ }^{13}$ Thus, there is interest in designing $\mathrm{C}^{\wedge} \mathrm{N}$ ligands that can mediate a blue-shift in the emission of the iridium complex without the presence of $\mathrm{C}_{\text {aryl }}-\mathrm{F}$ bonds. One promising avenue is to replace the phenyl ring of the $\mathrm{C}^{\wedge} \mathrm{N}$ ligands with an electron-poor heterocycle. The incorporation of a nitrogen atom within the phenyl ring of the $\mathrm{C}^{\wedge} \mathrm{N}$ ligands, such as with $2^{\prime}, 6^{\prime}$-difluoro-2, $3^{\prime}$-bipyridine,${ }^{14}$ resulted in an enhanced blue-shifted character of the complex compared to dFppy. These complexes utilise the electron-withdrawing properties of the cyclometalated pyridine to stabilise the HOMO energy in concert with the fluorine atoms on the pyridine ring. The fluorine atoms can be replaced with ambivalent methoxy groups (inductively electron-withdrawing when meta-substituted, $\sigma_{m}=+0.12$, and electron-donating when para-substituted, $\left.\sigma_{p}=-0.27\right)^{15}$ that blueshift the emission when situated at the $2^{\prime}, 6^{\prime}$-positions of the cyclometalating ring, and provide an effective fluorine-free alternative to the difluorophenyl moiety of dFppy as a strategy for blue-shifting the emission of these complexes. ${ }^{16}$
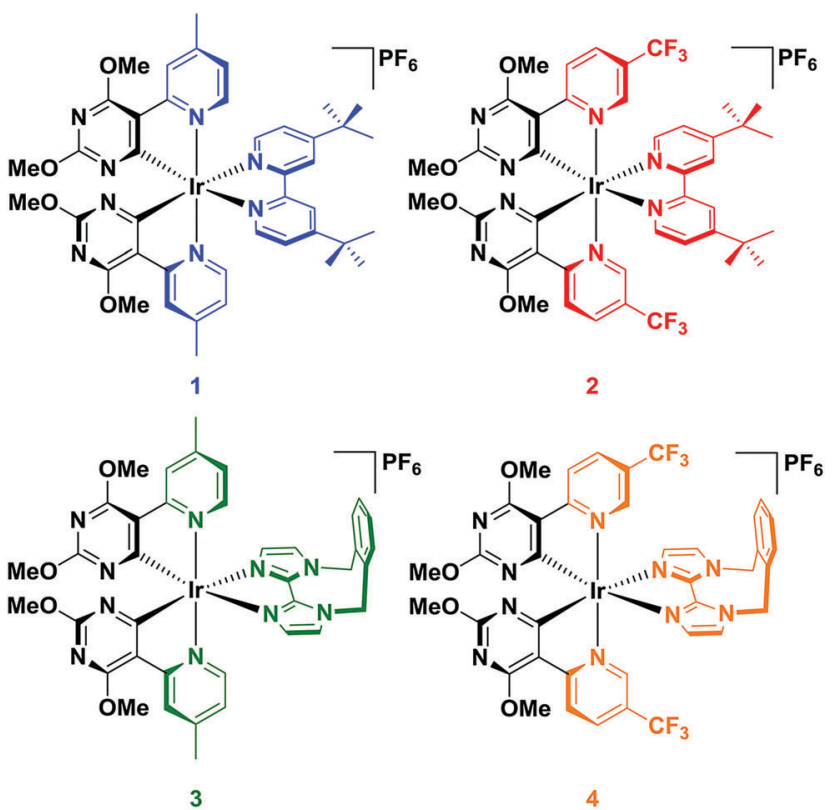

Chart 1 Complexes synthesised and characterised in this study.

Other fluorine-free cyclometalating heterocycles have also recently been explored. For example, cyclometalated 1-methyl2-(2'-pyridyl)pyridinium and 1-methyl-3-(2'-pyridyl)pyridinium ligands have been employed to generate blue-green cationic iridium complexes. ${ }^{17}$ Cyclometalated pyridylpyrimidines, which incorporate two nitrogen atoms into the cyclometalating ligand framework, have also been shown to be effective in blue-shifting the emission of neutral iridium complexes but so far no cationic examples have been reported. ${ }^{18}$

Four complexes were investigated in this study by employing combinations of four different ligands (Chart 1). For the $\mathrm{C}^{\wedge} \mathrm{N}$ ligands, the same cyclometalating pyrimidyl ring (2,4-dimethoxypyrimidine) was chosen, wherein the non-coordinating carbon atoms of the pyrimidine ring were substituted with methoxy groups. The pyridyl ring of the $\mathrm{C}^{\wedge} \mathrm{N}$ ligand was varied either to contain a methyl group para to the metal centre [5-(4-methylpyridin2-yl)-2,4-dimethoxypyrimidine, Mepypyrm] or to contain a trifluoromethyl group para to the pyrimidyl ring [5-(5-(trifluoromethyl)pyridine-2-yl)-2,4-dimethoxypyrimidine, $\mathrm{CF}_{3}$ pypyrm]. For the $\mathrm{N}^{\wedge} \mathrm{N}$ ligands, 4,4'-di-tert-butyl-2,2'-bipyridine (dtBubpy) and the rigid biimidazole ligand 1, $1^{\prime}$-( $\alpha, \alpha^{\prime}-$-oxylylene)-2, $2^{\prime}$-biimidazole (o-Xylbiim) were investigated. dtBubpy was used as a reference ancillary ligand, as it is one of the most commonly used $\mathrm{N}^{\wedge} \mathrm{N}$ ligands for LEECs, forming complexes in combination with both Mepypyrm (complex 1) or $\mathrm{CF}_{3}$ pypyrm (complex 2). We also employed $o$-Xylbiim in combination with Mepypyrm (complex 3) and $\mathrm{CF}_{3}$ pypyrm (complex 4), as we have previously shown that it is effective in blue-shifting the emission properties of $\left[\operatorname{Ir}\left(\mathrm{C}^{\wedge} \mathrm{N}\right)_{2}\left(\mathrm{~N}^{\wedge} \mathrm{N}\right)\right]^{+}$ complexes while also enhancing their photoluminescence quantum yields, $\Phi_{\mathrm{PL}} \cdot{ }^{19}$

Given the paucity of cationic iridium complexes bearing cyclometalated heterocycles, it is helpful to compare complexes 1-4 to reference complexes with well-characterised photophysical properties (Chart 2). Complex R1 employs the most commonly 


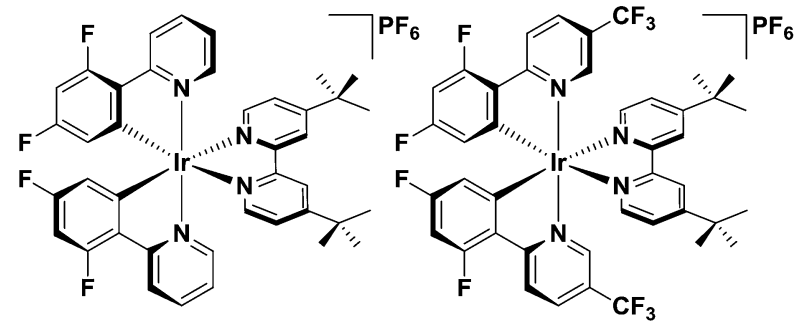

R1

R2

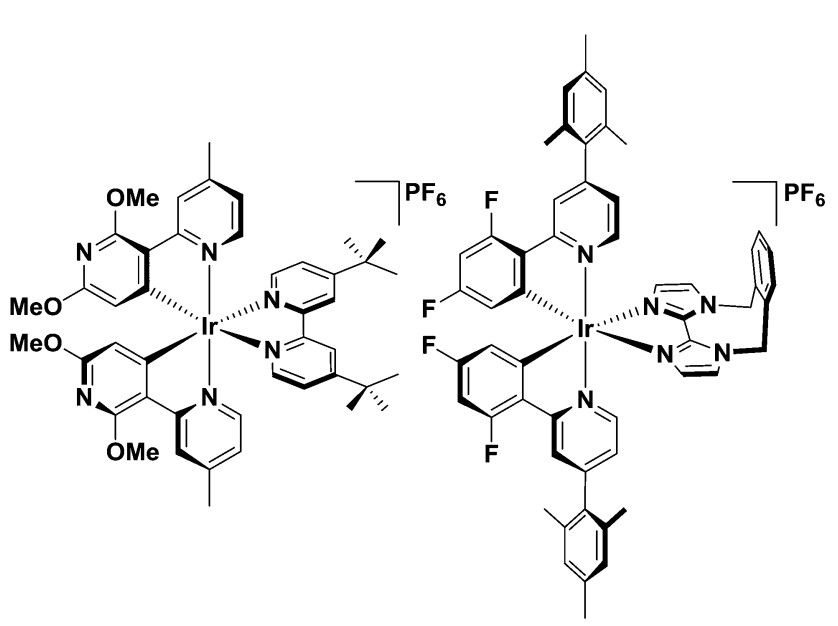

R3

R4

Chart 2 Reference complexes for this study.

used $\mathrm{C}^{\wedge} \mathrm{N}$ ligand, dFppy, to blue-shift the emission of iridium(III) complexes and thus serves as a benchmark complex. Complex R2, like complexes $\mathbf{2}$ and $\mathbf{4}$, has a $-\mathrm{CF}_{3}$ substituent incorporated into the pyridine ring of the $\mathrm{C}^{\wedge} \mathrm{N}$ ligand [2-(2,4-difluorophenyl)5-(trifluoromethyl)pyridine, $\mathrm{dFCF}_{3}$ ppy] and thus is useful to understand the influence of this substituent. Complex R3 is structurally very similar to $\mathbf{1}$ except that the cyclometalating heterocycle is a pyridine and not a pyrimidine $\left(2^{\prime}, 6^{\prime}\right.$-dimethoxy4-methyl-2,3'-bipyridine, 5-Mepypy). The comparison between R3 and $\mathbf{1}$ provides a basis to understand the effects of the additional nitrogen atom contained within the pyrimidine ring on the optoelectronic properties of the complex. Finally, complex R4, a very efficient blue emitter recently reported by us, ${ }^{19 b}$ contains the $o$-Xylbiim $\mathrm{N}^{\wedge} \mathrm{N}$ ligand $\left(\lambda_{\mathrm{PL}}=459 \mathrm{~nm}, \Phi_{\mathrm{PL}}=90 \%\right.$ in $\left.\mathrm{MeCN}\right)$.
The $\mathrm{C}^{\wedge} \mathrm{N}$ ligand for $\mathbf{R 4}$, [2-(2,4-difluorophenyl)-4-mesitylpyridine, dFMesppy], is electronically indistinct from dFppy, since the orthogonal conformation of the mesityl ring effectively deconjugates this group from the $\mathrm{C}^{\wedge} \mathrm{N}$ chromophore; we and others have shown that the mesityl group can enhance the $\Phi_{\mathrm{PL}}$ of the complex. $^{19 b, 20}$

\section{Results and discussion}

\section{Synthesis}

The two $\mathrm{C}^{\wedge} \mathrm{N}$ ligands were each synthesised in two steps (Scheme 1). Lithiation of 5-bromo-2,4-dimethoxypyrimidine with $n$-BuLi and quenching with trimethylborate afforded, after hydrolysis with $\mathrm{HCl}$, the corresponding boronic acid. Both $\mathrm{C}^{\wedge} \mathrm{N}$ ligands were then obtained through a Suzuki-Miyaura ${ }^{21}$ crosscoupling reaction with the appropriate substituted halopyridine. The $o$-Xylbiim $\mathrm{N}^{\wedge} \mathrm{N}$ ligand was synthesised as previously reported. ${ }^{19 a}$ The synthesis of the chloro-bridged dimers proceeded by refluxing the $\mathrm{C}^{\wedge} \mathrm{N}$ ligand in 2-ethoxyethanol with $[\operatorname{Ir}(\mathrm{COD})(\mu-\mathrm{Cl})]_{2}$ as the iridium source. ${ }^{15 a, 22}$ Complexes 1-4 were obtained following cleavage of the isolated crude dimers with an excess of $\mathrm{N}^{\wedge} \mathrm{N}$ ligand in refluxing $\mathrm{DCM} / \mathrm{MeOH}$ solution. The anion metathesis step was initially carried out using $\mathrm{NH}_{4} \mathrm{PF}_{6}$, but to avoid protonation of the pyrimidine rings on the complexes (vide infra) $\mathrm{KPF}_{6}$ was used subsequently instead (Scheme 2).

\section{Structural characterisation}

All complexes were comprehensively characterised using ${ }^{1} \mathrm{H}$, ${ }^{13} \mathrm{C}$ and, for complexes 2 and $4,{ }^{19} \mathrm{~F}$ NMR spectroscopy, along with high resolution mass spectrometry (HRMS) and elemental analysis (EA). Additionally, the structures of 1-4 were determined by single crystal X-ray diffraction.

In the solid-state, all four complexes show the expected distorted octahedral geometry about the iridium centre, ${ }^{19 b, 23}$ with two $\mathrm{C}^{\wedge} \mathrm{N}$ ligands coordinating through the pyridyl nitrogen atoms in a mutually trans configuration and the cyclometalating carbon atoms of the pyrimidine rings mutually cis to each other. The coordination sphere is completed by coordination through the nitrogen atoms of the $\mathrm{N}^{\wedge} \mathrm{N}$ ligands (Fig. 1). We were surprised to observe that in contrast to complexes $\mathbf{1}$ and $\mathbf{2}$, the crystal structures of $\mathbf{3}$ and $\mathbf{4}$ are not monocationic. In both cases one of the pyrimidyl nitrogen atoms of each of the complexes is

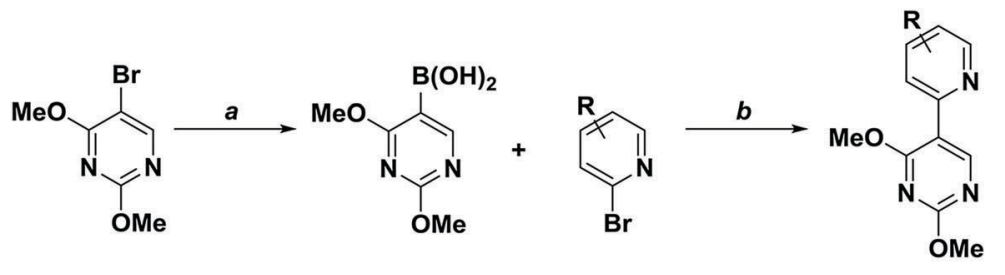

\begin{tabular}{ccr} 
Ligand: $\begin{array}{c}\text { Mepypyrm } \\
\text { CF }_{3} \text { pypyrm }\end{array} \quad$ 4-Me & Yield $=70 \%$ \\
\hline$-C_{3}$ & $84 \%$
\end{tabular}

Scheme 1 Synthesis of $\mathrm{C}^{\wedge} \mathrm{N}$ ligands. Reagents and conditions: ${ }^{a}$ (i) $n$-BuLi (1.3 equiv., $2.5 \mathrm{M}$ in hexanes), THF, $\mathrm{N}_{2},-78{ }^{\circ} \mathrm{C}, 1 \mathrm{~h}$; (ii) $\mathrm{B}(\mathrm{OMe}){ }_{3}(1.5 \mathrm{equiv}$.), rt, $16 \mathrm{~h}$; (iii) $\mathrm{HCl}, 16 \mathrm{~h}$, rt. ${ }^{b} \mathrm{~K}_{2} \mathrm{CO}_{3}$ (3.0 equiv.), 1,4-dioxane/water (2:1 v/v), $\mathrm{Pd}\left(\mathrm{PPh}_{3}\right)_{4}(5 \mathrm{~mol} \%), 80{ }^{\circ} \mathrm{C}, 16 \mathrm{~h}$. 


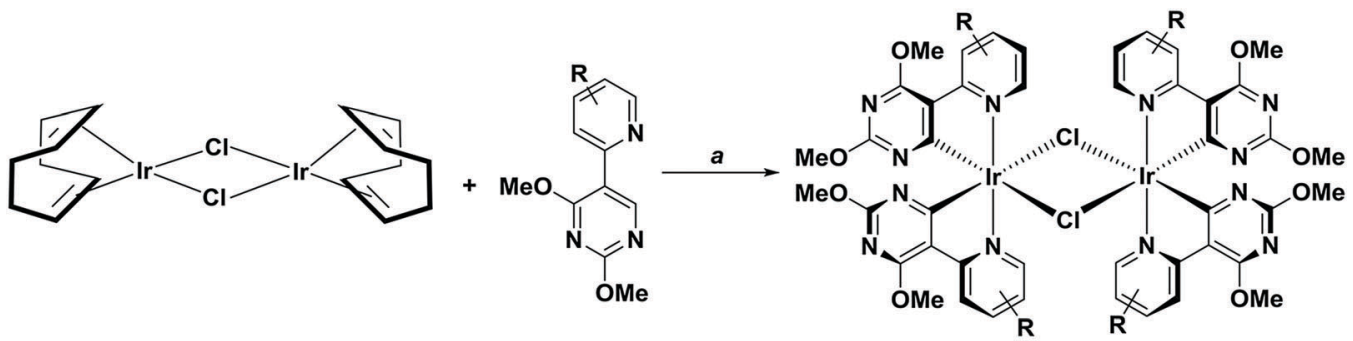

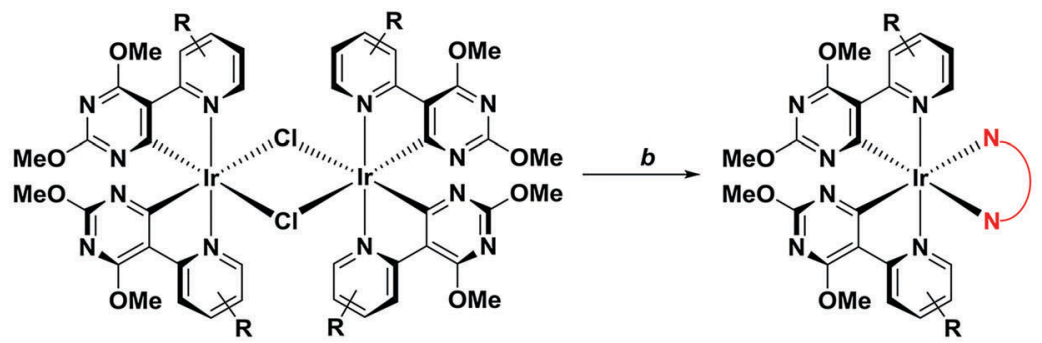

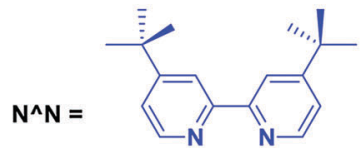

$\mathbf{R}=$

4-Me (98\%)

Complex

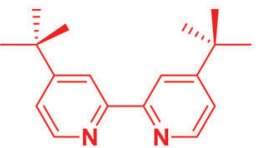

5- $\mathrm{CF}_{3}(95 \%)$

2

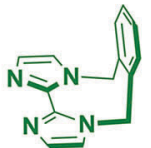

4-Me (67\%)

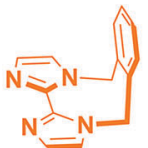

$5-\mathrm{CF}_{3}(70 \%)$

Scheme 2 Synthesis of 1-4. Reagents and conditions: ${ }^{a} 2-\mathrm{EtOC}_{2} \mathrm{H}_{4} \mathrm{OH}, 110{ }^{\circ} \mathrm{C}, \mathrm{N}_{2}, 3 \mathrm{~h} .{ }^{b}$ (i) $\mathrm{CH}_{2} \mathrm{Cl}_{2} / \mathrm{MeOH}(1: 1 \mathrm{v} / \mathrm{v}), 40{ }^{\circ} \mathrm{C}, 19 \mathrm{~h}, \mathrm{~N}_{2}$; (ii) excess $\mathrm{KPF} 6$ (aq.).
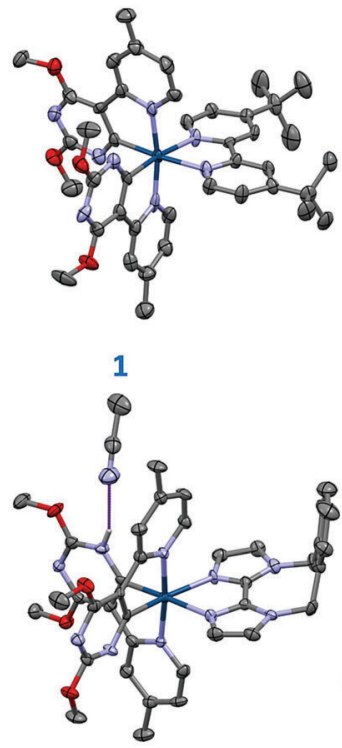

3- $\mathrm{H}^{+}{ }^{+} \cdot . \mathrm{MeCN}$

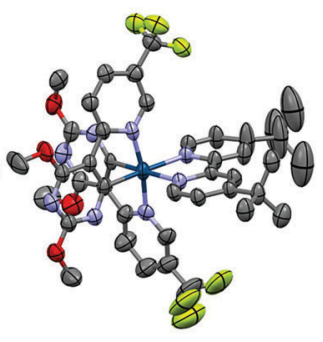

2

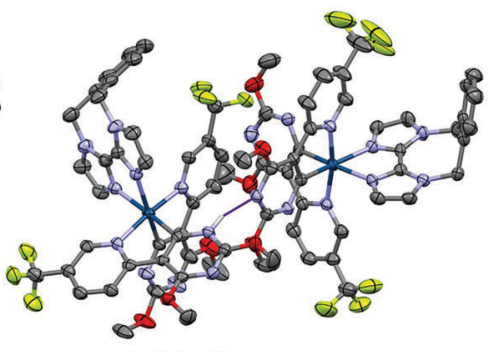

4- $\mathrm{H}^{+} \cdots 4$
Fig. 1 X-ray crystal structures of complexes $1-4$, thermal ellipsoids are drawn at the $50 \%$ probability level. Counterions, $\mathrm{C}-\mathrm{H}$ hydrogen atoms and non-hydrogen bonding solvent molecules have been removed for clarity. Atom labelling: hydrogen (light grey), carbon (grey), nitrogen (blue), oxygen (red), fluorine (yellow), and iridium (dark blue). Hydrogen bonding of the protonated pyrimidine rings in $\mathbf{3}$ and $\mathbf{4}$ is denoted with a purple line.

protonated, which is hypothesized to arise from the initial use of $\mathrm{NH}_{4} \mathrm{PF}_{6}$ as the anion metathesis reagent. In the case of 3 , the complex is a dication $\left(3-\mathrm{H}^{+}\right)$with two $\mathrm{PF}_{6}{ }^{-}$anions present for charge balance and a hydrogen bond $[\mathrm{N} \cdots \mathrm{N} 2.14(6) \AA]$ between the protonated pyrimidine ring and an acetonitrile solvent molecule. Complex 4 crystallises as a dimeric pair of protonated $\left(4-\mathbf{H}^{+}\right)$and non-protonated (4) complexes, which form a tight hydrogen bond $[\mathrm{N} \cdots \mathrm{N}$ 1.98(5) $\AA]$ between the protonated pyrimidine ring of $\mathbf{4}-\mathbf{H}^{+}$and the non-protonated pyrimidine ring of 4 . Thus, in the crystal structure there are three $\mathrm{PF}_{6}{ }^{-}$ anions for charge balance: one for each cyclometalated complex, and one for the additional proton.

For complexes $\mathbf{1}$ and $\mathbf{2}$, an unusual structural feature is observed, where only one of the $\operatorname{Ir}-\mathrm{C}_{\mathrm{C}^{\wedge} \mathrm{N}}$ bond lengths is shorter than the Ir- $\mathrm{N}_{\mathrm{C}^{\wedge} \mathrm{N}}$ bond lengths from the same $\mathrm{C}^{\wedge} \mathrm{N}$ ligand (Table 1). This is not typical of cyclometalated iridium complexes as the Ir- $\mathrm{C}_{\mathrm{C}^{\wedge N}}$ bonds are generally considered to be stronger than the

Table 1 Selected structural parameters for complexes 1-4

\begin{tabular}{|c|c|c|c|c|c|}
\hline \multirow[b]{2}{*}{ Complex } & \multicolumn{3}{|c|}{ Bond length $(\AA)$} & \multicolumn{2}{|c|}{ Bond angle $\left({ }^{\circ}\right)$} \\
\hline & Ir-C & $\operatorname{Ir}-\mathrm{N}_{\mathrm{C}^{\wedge} \mathrm{N}}$ & $\mathrm{Ir}-\mathrm{N}_{\mathrm{N}^{\wedge} \mathrm{N}}$ & $\mathrm{N}-\mathrm{Ir}-\mathrm{C}$ & N-Ir-N \\
\hline \multirow[t]{2}{*}{1} & 1.993(19) & $2.030(19)$ & $2.134(16)$ & $79.5(8)$ & $75.6(6)$ \\
\hline & $2.014(17)$ & $1.949(19)$ & $2.146(14)$ & $79.5(8)$ & \\
\hline \multirow[t]{2}{*}{2} & $1.997(15)$ & $1.98(2)$ & $2.138(13)$ & $80.7(8)$ & $76.6(5)$ \\
\hline & $1.950(17)$ & $2.04(2)$ & $2.119(15)$ & $80.7(8)$ & \\
\hline \multirow[t]{2}{*}{$3-\mathbf{H}^{+}$} & $1.968(7)$ & $2.049(6)$ & $2.109(6)$ & $79.9(3)$ & $75.5(2)$ \\
\hline & $1.998(5)$ & $2.059(6)$ & $2.153(4)$ & $78.9(3)$ & \\
\hline \multirow[t]{2}{*}{$4-H^{+}$} & $1.980(6)$ & $2.051(5)$ & $2.099(5)$ & $80.2(2)$ & 75.85(19) \\
\hline & $1.970(6)$ & $2.040(5)$ & $2.138(5)$ & $79.9(2)$ & \\
\hline \multirow[t]{2}{*}{4} & $1.964(6)$ & $2.029(5)$ & $2.118(5)$ & $79.8(2)$ & $75.6(2)$ \\
\hline & $1.989(6)$ & $2.035(5)$ & $2.136(5)$ & $79.7(2)$ & \\
\hline
\end{tabular}



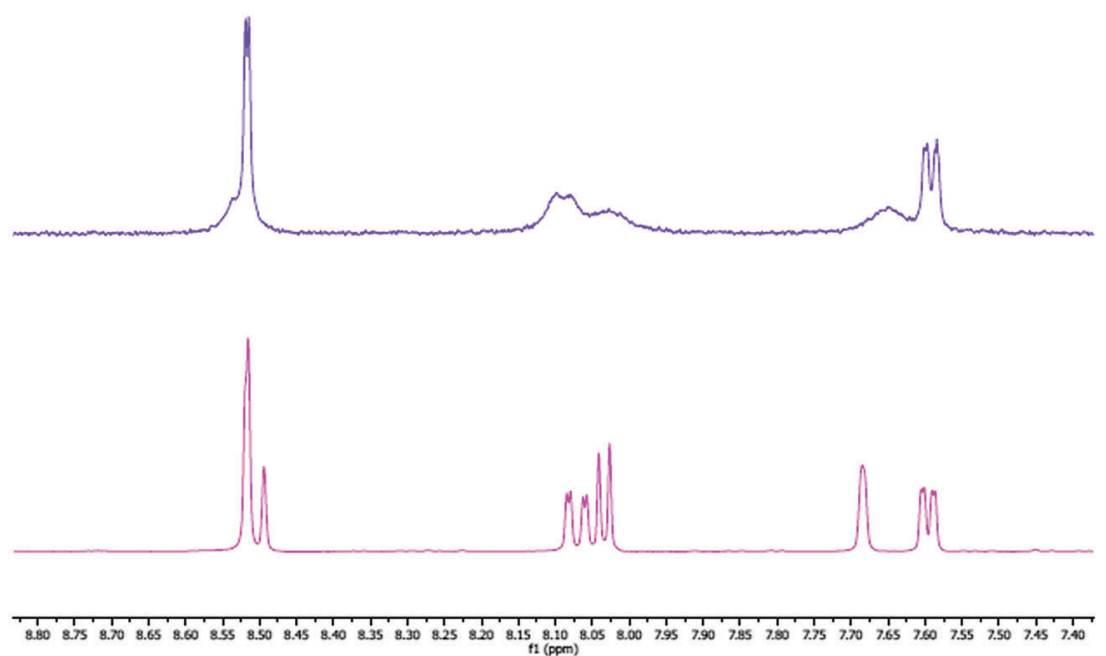

Fig. 2 Aromatic region of the ${ }^{1} \mathrm{H}$ NMR spectra for 2 in $\mathrm{CD}_{3} \mathrm{CN}$ prepared using $\mathrm{NH}_{4} \mathrm{PF}_{6}$ (top) and $\mathrm{KPF}$ (bottom) as the anion metathesis reagent.

Ir- $\mathrm{N}_{\mathrm{C} \wedge \mathrm{N}}$ bonds, and thus they would all be expected to be shorter. By contrast, complexes $\mathbf{3}-\mathbf{H}^{+}, \mathbf{4}$ and $\mathbf{4}-\mathbf{H}^{+}$show more conventional behaviour.

In solution, batches of 1 and 2 prepared using $\mathrm{NH}_{4} \mathrm{PF}_{6}$ as the anion metathesis reagent gave unusually broad and featureless ${ }^{1} \mathrm{H}$ NMR spectra, which were attributed to the protonation of the pyrimidine rings, a feature observed in the crystal structures of 3 and 4. Fig. 2 shows a comparison of the ${ }^{1} \mathrm{H}$ NMR spectra of batches of complex 2 prepared using $\mathrm{NH}_{4} \mathrm{PF}_{6}$ and $\mathrm{KPF}_{6}$, showing the sharper features present for the batch prepared using $\mathrm{KPF}_{6}$.

In order to ensure valid comparison across the series of complexes, all photophysical measurements were carried out on samples prepared using $\mathrm{KPF}_{6}$. Elemental analysis confirmed that they are in their monocationic forms.

The ${ }^{1} \mathrm{H}$ NMR spectra of non-protonated samples of complexes $\mathbf{3}$ and $\mathbf{4}$ are broadened, as a result of the expected fluxional motion of the $o$-Xylbiim ligand, which is slow on the NMR timescale. Heating the samples resulted in simplification of the spectra due to the dynamic pseudo $C_{2}$-symmetric geometry (Fig. S15 and S17 in the ESI $\dagger$ ). Eyring analysis on the barrier to inversion for $\mathbf{3}$ and $\mathbf{4}$ gave similar activation energies to each other $\left(\Delta G^{\ddagger}=82.9\right.$ and $83.2 \mathrm{~kJ} \mathrm{~mol}^{-1}$ for complexes 3 and 4 , respectively) as well as to the previously reported complexes $\left(\Delta G^{\ddagger}=72.2-82.3 \mathrm{~kJ} \mathrm{~mol}^{-1}\right) .{ }^{19}$

\section{Electrochemical properties}

Electrochemical measurements on 1-4 were carried out in MeCN. The cyclic voltammetry (CV) traces are shown in Fig. 3 while the relevant electrochemical data are given in Table 2. The first oxidation wave in $\mathbf{1}$ was found to be quasi-reversible while those of 2-4 were found to be irreversible. The DFT calculations point to HOMOs that reside on both the $\operatorname{Ir}(\mathrm{III})$ ion and the aryl ring of the $\mathrm{C}^{\wedge} \mathrm{N}$ ligands. Thus, the oxidation of all the complexes is inferred as the removal of an electron from the admixture of the $\operatorname{Ir}(\mathrm{III})$ metal centre and the pyrimidine rings of the $\mathrm{C}^{\wedge} \mathrm{N}$ ligands (Fig. 4). The oxidation potential for $\mathbf{1}$

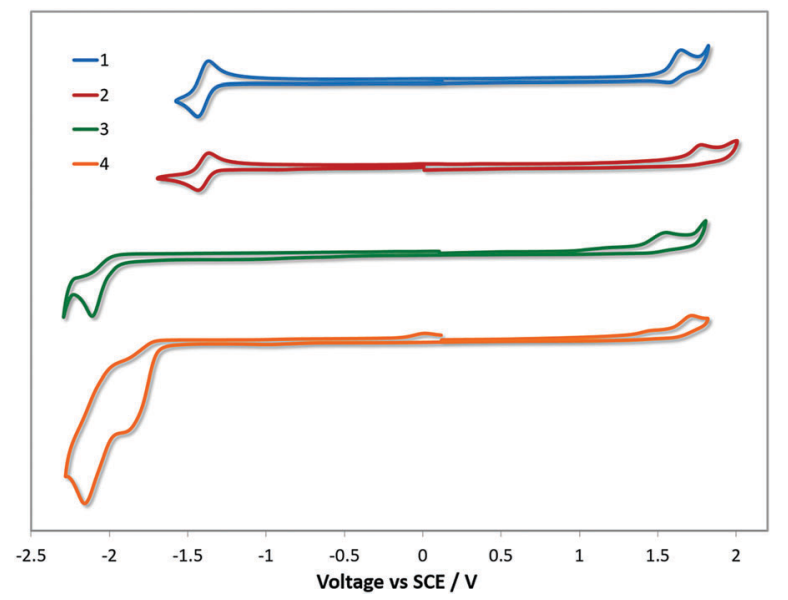

Fig. $3 \mathrm{CV}$ traces of complexes 1-4 in MeCN solution, reported versus $\mathrm{SCE}\left(\mathrm{Fc} / \mathrm{FC}^{+}=0.38 \mathrm{~V}\right.$ in $\left.\mathrm{MeCN}\right) .^{26}$ Scan rates were at $100 \mathrm{mV} \mathrm{s}^{-1}$ and are in the positive scan direction.

$\left[E_{\mathrm{pa}}^{(\mathrm{ox})}=1.53 \mathrm{~V}\right]$ is cathodically shifted compared to $2\left[E_{\mathrm{pa}}^{(\mathrm{ox})}=1.70 \mathrm{~V}\right]$ indicating that the $-\mathrm{CF}_{3}$ group is exerting a stabilising influence on the HOMO of 2 . This is consistent with the analogous comparison of complexes $\mathbf{R} 1\left[E_{1 / 2}^{(\text {ox })}=1.60 \mathrm{~V}\right]$ and $\mathbf{R} 2\left[E_{1 / 2}^{(\text {ox })}=1.69 \mathrm{~V}\right]$ though the effect is more pronounced in $\mathbf{2}$ compared to $\mathbf{1}$ due to the concomitant removal of the electron-donating methyl group, which is not present in R1. The higher energy calculated for the HOMO of 1 $\left(E_{\mathrm{HOMO}}=-5.93 \mathrm{eV}\right)$ compared to that of $2\left(E_{\mathrm{HOMO}}=-6.25 \mathrm{eV}\right)$ is in good agreement with the measured $0.17 \mathrm{~V}$ cathodic shift of the energy of the oxidation wave of $\mathbf{1}$ with respect to that of $\mathbf{2}$ (Table 2). A slightly less positive oxidation potential (difference of $0.07 \mathrm{~V}$ ) is observed for $\mathbf{1}$ compared to R1, which indicates that dFppy stabilises the HOMO in a similar manner to the Mepypyrm $\mathrm{C}^{\wedge} \mathrm{N}$ ligand, with the difference in the oxidation potential being attributed to the presence of the electron donating methyl group on the pyridine. Indeed, similar small differences in the oxidation potential have been found in changing the $\mathrm{C}^{\wedge} \mathrm{N}$ ligands in heteroleptic iridium complexes from dFppy to dFMeppy where 
Table 2 Relevant electrochemical data for complexes 1-4

\begin{tabular}{lllllllllll}
\hline Cmpd & $E_{\mathrm{pa}(\mathrm{ox})}(\mathrm{V})$ & $E_{\mathrm{pc}(\mathrm{ox})}(\mathrm{V})$ & $E_{\mathrm{pc}(\mathrm{red})}(\mathrm{V})$ & $E_{\mathrm{pa}(\mathrm{red})}(\mathrm{V})$ & $E_{\mathrm{HOMO}}{ }^{b}(\mathrm{eV})$ & $E_{\mathrm{LUMO}}{ }^{b}(\mathrm{eV})$ & $\Delta E_{\mathrm{redox}}(\mathrm{V})$ & $E_{\mathrm{HOMO}}{ }^{c}(\mathrm{eV})$ & $E_{\mathrm{LUMO}}(\mathrm{eV})$ & $\left|E_{\mathrm{LUMO}-\mathrm{HOMO}}\right|^{c}(\mathrm{eV})$ \\
\hline $\mathbf{1}$ & $1.53^{d}$ & $1.73^{d}$ & $-1.39^{e}$ & $-1.45^{e}$ & -5.95 & -3.03 & 2.92 & -5.93 & -2.33 \\
$\mathbf{2}$ & $1.70^{f}$ & - & $-1.38^{e}$ & $-1.45^{e}$ & -6.12 & -3.04 & 3.08 & -6.25 & -2.48 \\
$\mathbf{3}$ & $1.46^{f}$ & - & $-2.00^{f}$ & - & -5.88 & -2.42 & 3.46 & -5.81 & -1.55 \\
$\mathbf{4}$ & $1.65^{f}$ & - & $-1.74^{f}$ & - & -6.07 & -2.68 & 3.39 & -6.12 & -2.00 & 4.26 \\
$\mathbf{R 1}^{19 b}$ & $1.60^{g}$ & - & -1.36 & - & -6.02 & -3.06 & 2.96 & - & - & - \\
$\mathbf{R 2}^{25}$ & $1.69^{g}$ & - & -1.37 & - & -6.11 & -3.05 & 3.06 & - & - \\
$\mathbf{R 3}^{16 a}$ & $1.51^{g}$ & - & -1.41 & - & -5.93 & -3.01 & 2.92 & - & - \\
$\mathbf{R 4}^{19 b}$ & $1.37^{g}$ & - & -1.99 & - & -5.79 & -2.43 & 3.36 & - & - & -
\end{tabular}

${ }^{a}$ Measurements were carried out in $\mathrm{MeCN}$ at a scan rate of $100 \mathrm{mV} \mathrm{s}^{-1}$ with $\mathrm{Fc} / \mathrm{Fc}^{+}$employed as an internal standard, and data are reported $v s$.

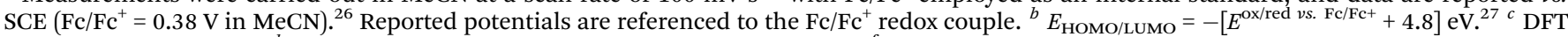
calculated energy in eV. ${ }^{d}$ Quasi-reversible redox wave. ${ }^{e}$ Reversible redox wave. ${ }^{f}$ Irreversible redox wave. ${ }^{g}$ Reported refer to $E_{1 / 2}$ values.

the only difference is the presence of a methyl group at the 4-position of the pyridine ring. ${ }^{24}$ There is only a small difference in the oxidation potential measured for $\mathbf{R} 3\left[E_{1 / 2}^{(\mathrm{ox})}=1.51 \mathrm{~V}\right]$ compared to 1 , demonstrating that the additional nitrogen atom in the pyrimidine has only a modest influence on the HOMO. In contrast to $\mathbf{1}$ and $\mathbf{R} \mathbf{1}$, complex $\mathbf{2}$ has a virtually identical oxidation potential to $\mathbf{R} 2\left[E_{1 / 2}^{(\text {ox })}=1.69 \mathrm{~V}\right]$, demonstrating the importance of the influence of the $-\mathrm{CF}_{3}$ substitution on the $\mathrm{C}^{\wedge} \mathrm{N}$ ligand design.

As was observed for $\mathbf{1}$ and 2, the oxidation potential of $\mathbf{3}$ $\left[E_{\mathrm{pa}}^{(\mathrm{ox})}=1.46 \mathrm{~V}\right]$ is cathodically shifted compared to $4\left[E_{\mathrm{pa}}^{(\mathrm{ox})}=\right.$ $1.65 \mathrm{~V}]$. Similar to the trends predicted for 1 and 2, the DFT predicted HOMO energies of $3\left(E_{\mathrm{HOMO}}=-5.81 \mathrm{eV}\right)$ and 4 $\left(E_{\mathrm{HOMO}}=-6.12 \mathrm{eV}\right)$ are in line with their oxidation potentials where there is a good agreement with the measured $0.19 \mathrm{~V}$ cathodic shift of the energy of the oxidation wave of 3 with respect to that of $\mathbf{4}$ (Table 1). Both the $o$-Xylbiim complexes 3 and 4 show marginally cathodically shifted oxidation waves compared to their corresponding dtBubpy analogues $\mathbf{1}$ and $\mathbf{2}$, which is a consequence of the electron-releasing nature of the biimidazole $\mathrm{N}^{\wedge} \mathrm{N}$ ligand. This behaviour is corroborated by the DFT calculated energies of the HOMOs of 1 vs. 3 and 2 vs. 4 (Table 2). A similar comparison exists with complexes R1 and $\mathbf{R 4}\left[E_{1 / 2}^{(\text {ox })}=1.37 \mathrm{~V}\right]$.

Determining trends for the observed reduction potentials is less straightforward. For complexes $\mathbf{1}$ and $\mathbf{2}$, a reversible reduction at virtually the same potential $\left[E_{\mathrm{pc}}^{(\mathrm{red})}=-1.39 \mathrm{~V}\right.$ for $\mathbf{1}$ and $-1.38 \mathrm{~V}$ for 2] was attributed to the reduction of the dtBubpy ligand, an assignment supported by DFT calculations. By contrast, the LUMO is predicted by DFT to be on the biimidazole (biim) part of the $o$-Xylbiim ligand for 3 and on the $\mathrm{CF}_{3}$ pypyrm moiety for 4 (Fig. 4). The destabilisation of the LUMO of complex $1\left(E_{\text {LUMO }}=-2.33 \mathrm{eV}\right)$ explains the small cathodic shift of $10 \mathrm{mV}$ measured for its first reduction wave $\left[E_{\mathrm{pc}}^{(\mathrm{red})}=-1.39 \mathrm{~V}\right]$ in comparison with those of complex $2\left[E_{\mathrm{LUMO}}=\right.$ $\left.-2.48 \mathrm{eV} ; E_{\mathrm{pc}}^{(\mathrm{red})}=-1.38 \mathrm{~V}\right]$. Complexes R1-R3 likewise show reversible reduction waves in a similar range $\left[E_{1 / 2}^{(\text {red })}=-1.36 \mathrm{~V}\right.$ for $\mathbf{R} 1,-1.37$ for $\mathbf{R} 2$ and -1.41 for R3]. For complexes $\mathbf{3}$ and $\mathbf{4}$, the reduction waves are observed at significantly lower potentials $\left[E_{\mathrm{pc}}^{(\mathrm{red})}=-2.00 \mathrm{~V}\right.$ for $3,-1.74 \mathrm{~V}$ for 4$]$ and are irreversible in nature. The nature of the reductions in 3 and 4 can be inferred by scanning beyond the reduction potentials of the dtBubpy ligand for complexes 1 and 2 (Fig. S18 in the ESI $\dagger$ ).

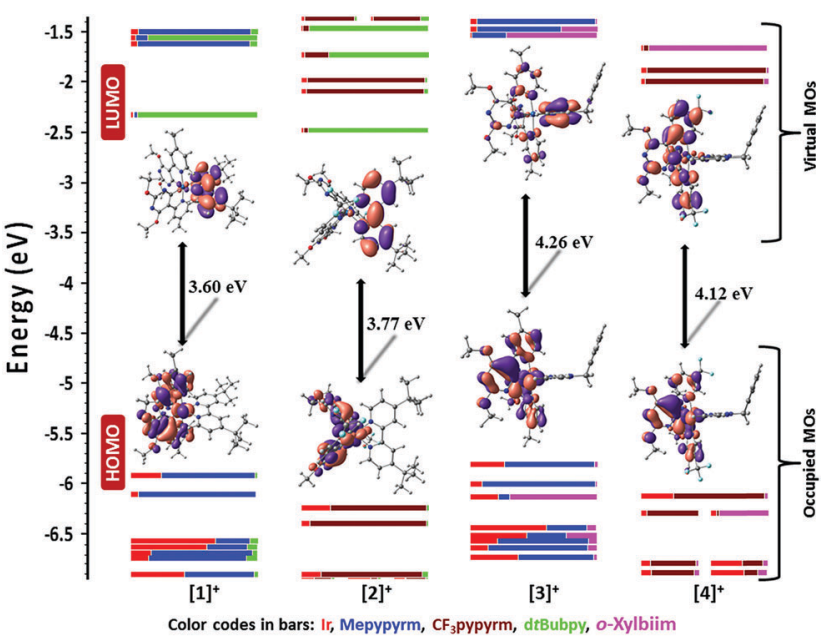

Fig. 4 Calculated frontier $\mathrm{MO}$ energies of $[\mathbf{1}]^{+},[\mathbf{2}]^{+},[3]^{+}$and $[4]^{+}$, obtained from DFT [B3LYP/SBKJC-VDZ for Ir(III) and 6-31G** for C, H, N, O, and F] with $\mathrm{CPCM}(\mathrm{MeCN})$ and $0.5 \mathrm{eV}$ threshold of degeneracy (orbitals with an isocontour value of 0.03$)$. Kohn-Sham MOs of $[1]^{+},[2]^{+},[3]^{+}$and $[4]^{+}$are also shown.

Complex 1 exhibits a second irreversible reduction at the same potential $\left[E_{\mathrm{pc}}^{(\mathrm{red})}=-2.00 \mathrm{~V}\right]$ as the reduction for 3, which strongly suggests reduction of the pyridine ring of the $\mathrm{C}^{\wedge} \mathrm{N}$ ligand. However, it is worth noting that the reduction wave in $\mathbf{R 4}$, which was attributed to the reduction of the $o$-Xylbiim ligand, is also at almost the same potential $\left[E_{1 / 2}^{(\text {red })}=-1.99 \mathrm{~V}\right]$. It is therefore plausible that the reduction wave of 3 is due to the reduction of the $\mathrm{N}^{\wedge} \mathrm{N}$ ligand, which is supported by the DFT calculations, where the LUMO is predicted to be on the biim moiety of the o-Xylbiim ligand (Fig. 4). For complex 4, there are at least two observable reduction processes that can be attributed to either or both the reduction of the $o$-Xylbiim ligand and/or the pyridyl ring of the $\mathrm{C}^{\wedge} \mathrm{N}$ ligand. A similar set of multi-electron reductions is observed for complex 2 $\left[E_{\mathrm{pc}}^{(\mathrm{red})}=-1.86 \mathrm{~V}\right]$, and these are anodically shifted compared to the second reduction observed for 1 . This behaviour mirrors the anodic shift observed in the first reduction of $\mathbf{4}$ compared to 3 and is consistent with the direct reduction of a more electron deficient $\mathrm{CF}_{3}$-substituted pyridine ring, an assignment corroborated by DFT calculations. The predicted destabilisation of the LUMO $\left(E_{\mathrm{LUMO}}=-1.55 \mathrm{eV}\right)$ explains the measured cathodic shift of $260 \mathrm{mV}$ in the $\mathrm{CV}$ of $3\left[E_{\mathrm{pc}}^{(\mathrm{red})}=-2.00 \mathrm{~V}\right]$ 


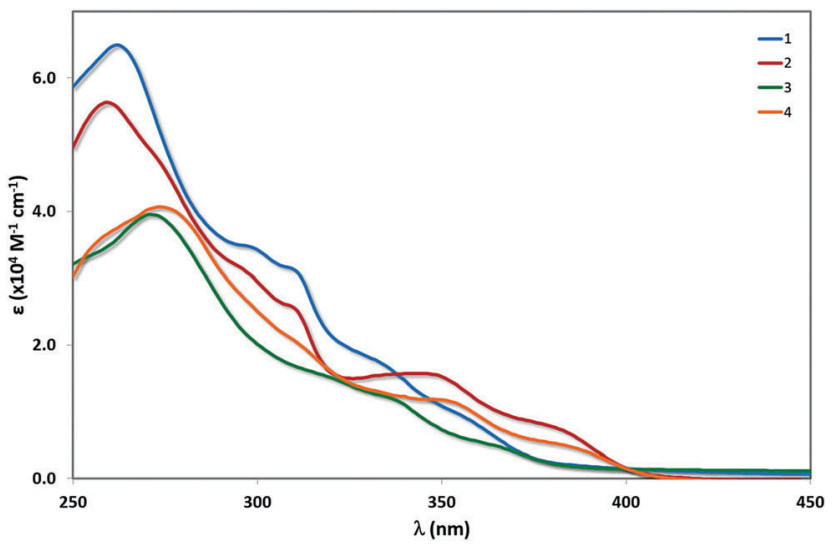

Fig. 5 UV-vis absorption spectra of complexes 1-4 in MeCN solution.

compared to that of $4\left[E_{\mathrm{LUMO}}=-2.00 \mathrm{eV} ; E_{\mathrm{pc}}^{(\mathrm{red})}=-1.74 \mathrm{~V}\right]$. Finally, complex $\mathbf{R 2}$ is reported to have a second reduction $\left[E_{1 / 2}^{(\mathrm{red})}=-1.68 \mathrm{~V}\right]$ that was attributed to the reduction of the $\mathrm{dFCF}_{3}$ ppy ligand in a similar regime to the first reduction of 4 . The electrochemically observed redox gap, $\Delta E_{\text {redox }}$, follows the order of $1(2.92 \mathrm{~V})<2(3.08 \mathrm{~V})<\mathbf{4}(3.39 \mathrm{~V})<$ and $\mathbf{3}(3.46 \mathrm{~V})$, and this trend is also in good agreement with the DFT predicted HOMO-LUMO energy gap, $\left|E_{\text {Номо-LUMo }}\right| ; 1(3.60 \mathrm{eV})<$ $2(3.77 \mathrm{eV})<4(4.12 \mathrm{eV})<$ and $3(4.26 \mathrm{eV})$ (Table 2).

\section{UV-vis absorption}

The UV-vis absorption spectra for 1-4 are shown in Fig. 5 and the molar absorptivity data are given in Table 3 . The predicted transitions obtained by TD-DFT calculations are tabulated for each complex in Tables S2-S5 (ESI $\dagger$ ). In the high-energy region of the spectrum $(250-325 \mathrm{~nm}), \pi-\pi^{*}$ transitions for all complexes dominate and the features of the spectra are determined by the nature of the $\mathrm{N}^{\wedge} \mathrm{N}$ ligand. The principal $\pi-\pi^{*}$ bands for complexes 1 and 2 are blue-shifted $\left(\lambda_{\mathrm{abs}}=264 \mathrm{~nm}\right.$ for 1 and $261 \mathrm{~nm}$ for $\left.2, \varepsilon \sim 60000 \mathrm{M}^{-1} \mathrm{~cm}^{-1}\right)$ and are more absorptive than that for 3 and $4\left(\lambda_{\mathrm{abs}}=268 \mathrm{~nm}\right.$ for 3 and $276 \mathrm{~nm}$ for 4 , $\varepsilon \sim 40000 \mathrm{M}^{-1} \mathrm{~cm}^{-1}$ ), which is in accordance with what was observed previously between complexes containing dtBubpy and $o$-Xylbiim as the $\mathrm{N}^{\wedge} \mathrm{N}$ ligand. This trend is perfectly in line with the TD-DFT predicted principal $\pi-\pi^{*}$ transition energies for complexes $1(259 \mathrm{~nm})$ and $2(255 \mathrm{~nm})$ compared to those of complexes $3(262 \mathrm{~nm})$ and $4(277 \mathrm{~nm})$. Except for complex 4, these transitions consist primarily of $\pi-\pi^{*}$ transitions localized on the $\mathrm{C}^{\wedge} \mathrm{N}$ ligand mixed, to a small degree, with some

Table 3 Absorption maxima and their corresponding molar absorptivities for complexes $\mathbf{1 - 4 ^ { a }}$

\begin{tabular}{ll}
\hline Complex & $\lambda_{\text {abs }}(\mathrm{nm})\left[\varepsilon\left(\times 10^{4} \mathrm{M}^{-1} \mathrm{~cm}^{-1}\right)\right]$ \\
\hline $\mathbf{1}$ & $264[6.49], 300[3.45], 311(\mathrm{sh})[3.08], 335[1.71], 361[0.90]$ \\
$\mathbf{2}$ & $261[5.61], 275(\mathrm{sh})[4.63], 297(\mathrm{sh})[3.10], 311[2.50]$, \\
& $350[1.53], 384[0.69]$ \\
$\mathbf{3}$ & $268[3.94], 322(\mathrm{sh})[1.46], 339[1.23], 369[0.41]$ \\
$\mathbf{4}$ & $276[4.05], 315(\mathrm{sh})[1.84], 352[1.16], 388[0.42]$ \\
${ }^{a}$ Measurements were carried out in MeCN.
\end{tabular}

ligand-to-ligand charge transfer from the $\mathrm{C}^{\wedge} \mathrm{N}$ ligands to the $\mathrm{N}^{\wedge} \mathrm{N}$ ligand, and $\operatorname{Ir}(\mathrm{d} \pi)$ to both $\mathrm{C}^{\wedge} \mathrm{N}$ and the ancillary ligands (metal-to-ligand charge transfer, ${ }^{1} \mathrm{MLCT}$ ). In addition, two bands are observed for 1 and $2\left(\lambda_{\mathrm{abs}}=300\right.$ and $311 \mathrm{~nm}$ for 1 and 297 and $311 \mathrm{~nm}$ for 2) that are not present for $\mathbf{3}$ and $\mathbf{4}$, which suggest that these bands involve uniquely the dtBubpy $\mathrm{N}^{\wedge} \mathrm{N}$ ligand. However, TD-DFT calculations predict that these transitions are mostly ${ }^{1} \mathrm{LC}$ transitions on the $\mathrm{C}^{\wedge} \mathrm{N}$ ligands with some ${ }^{1} \mathrm{MLCT} \operatorname{Ir}(\mathrm{d} \pi)$ to $\mathrm{C}^{\wedge} \mathrm{N}$ transition; the ${ }^{1} \mathrm{MLCT}$ character is more dominant for 2 (Tables S2 and S3, ESI $\dagger$ ).

At lower energies, the trends are reversed, with the absorption features insensitive to the nature of the $\mathrm{N}^{\wedge} \mathrm{N}$ ligand but strongly affected by the nature of the $\mathrm{C}^{\wedge} \mathrm{N}$ ligand. Complexes $\mathbf{1}$ and 3 have a pair of poorly resolved absorption bands $\left(\lambda_{\mathrm{abs}}=\right.$ 335 and $361 \mathrm{~nm}$ for 1 and 339 and $369 \mathrm{~nm}$ for 3). Complexes 2 and 4 have a similar pair of absorption bands but these bands are well resolved and red-shifted $\left(\lambda_{\text {abs }}=350\right.$ and $384 \mathrm{~nm}$ for 2 and 352 and $388 \mathrm{~nm}$ for 4). The similarity of the absorption spectra suggests that these bands are constituted of transitions localised on the $\mathrm{C}^{\wedge} \mathrm{N}$ ligands. However, their much lower absorptivity values compared to the higher energy absorption bands imply that they are not likely to be comprised of significant $\pi-\pi^{*}$ transitions. Instead, the lower absorptivities of these bands for the four complexes are indicative of ${ }^{1}$ MLCT charge transfer contributions from the metal to the pyridine of the $\mathrm{C}^{\wedge} \mathrm{N}$ ligand, as well as possibly from the methoxy substituents into the pyridyl rings (intra-ligand charge transfer, ${ }^{1}$ ILCT). However, TD-DFT calculations point to a predominant ${ }^{1} \mathrm{LC}_{\mathrm{C}^{\wedge} \mathrm{N}}$ transition mixed with some ${ }^{1} \mathrm{MLCT}$ from $\operatorname{Ir}(\mathrm{d} \pi)$ to the $\mathrm{C}^{\wedge} \mathrm{N}$ ligands for complexes 1 and 4 . Likewise, the transitions at $357 \mathrm{~nm}$ and $339 \mathrm{~nm}$ of 2 and 3, respectively, mainly possess ${ }^{1} \mathrm{LC}_{\mathrm{C}^{\wedge} \mathrm{N}}$ character with again some ${ }^{1} \mathrm{MLCT}$ character from $\operatorname{Ir}(\mathrm{d} \pi)$ to the $\mathrm{C}^{\wedge} \mathrm{N}$ ligands. The transition at $380 \mathrm{~nm}$ in 2 involves mainly a ligand-to-ligand charge transfer $\left({ }^{1} \mathrm{LLCT}\right)$ contribution from the $\mathrm{C}^{\wedge} \mathrm{N}$ ligands to dtBubpy, along with ${ }^{1} \mathrm{MLCT}$ from $\operatorname{Ir}(\mathrm{d} \pi)$ to the $\mathrm{N}^{\wedge} \mathrm{N}$ ligand (Tables S3 and S4, ESI $\dagger$ ). The transition at $369 \mathrm{~nm}$ in 3 is rather complicated and consists mostly of an ${ }^{1} \mathrm{LLCT}$ from the $\mathrm{C}^{\wedge} \mathrm{N}$ ligands to the $o$-Xylbiim ligand and ${ }^{1}$ MLCT from $\operatorname{Ir}(\mathrm{d} \pi)$ to both the ligands (Table S4, ESI $\dagger$ ). The redshift observed for complexes 2 and 4 corroborates this charge transfer assertion, due to the stabilisation of orbitals on the pyridyl ring by the electron-withdrawing $-\mathrm{CF}_{3}$ group, and is in accordance with an anodic shift in the second reduction potentials of $\mathbf{2}$ compared to $\mathbf{1}$ and the first reduction potential of 4 compared to 3 . Although the principal bands for complexes $\mathbf{1}$ and $\mathbf{3}$ are blue-shifted, there is weak absorption present in these two complexes beyond the onset of absorption for complexes 2 and $\mathbf{4}$, suggesting that the lowest energy transition is in fact higher in energy for complexes $\mathbf{2}$ and $\mathbf{4}$ than for $\mathbf{1}$ and $\mathbf{3}$.

\section{Emission spectroscopy}

The photophysical properties of these complexes were studied in MeCN solution at $298 \mathrm{~K}$. Their emission profiles are shown in Fig. 6, and the relevant photophysical data are given in Table 4. Complex 1 is a green emitter, with broad, unstructured emission that is characteristic of a mixed charge transfer state 


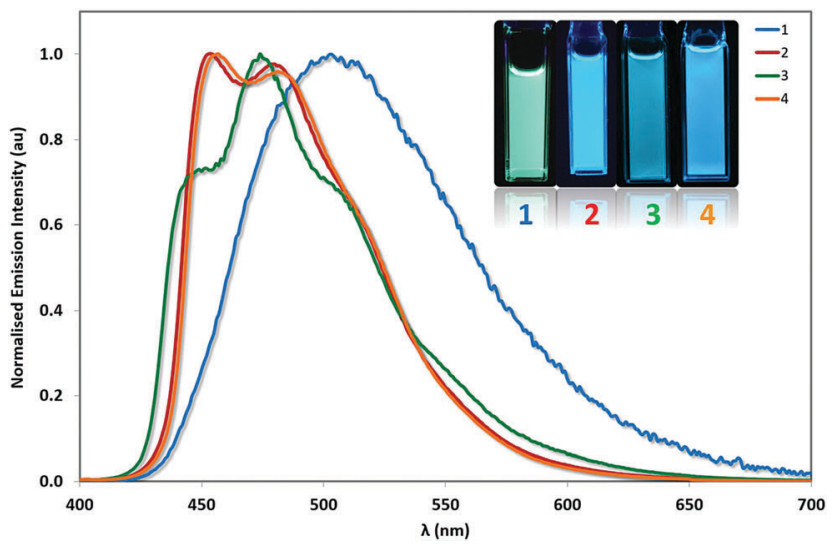

Fig. 6 Normalised emission spectra for complexes 1-4 in deaerated $\mathrm{MeCN}$ solution. $\lambda_{\text {exc }}: 360 \mathrm{~nm}$. Inset: $\mathrm{MeCN}$ solutions of complexes 1-4 illuminated under UV (365 nm) irradiation.

between both the metal to the $\mathrm{N}^{\wedge} \mathrm{N}$ ligand $\left({ }^{3} \mathrm{MLCT}\right)$ and the $\mathrm{C}^{\wedge} \mathrm{N}$ ligands to the $\mathrm{N}^{\wedge} \mathrm{N}$ ligand $\left({ }^{3} \mathrm{LLCT}\right)$. The mixed charge transfer nature of the emission spectrum of $\mathbf{1}$ is also supported by the DFT predicted $\mathrm{T}_{1}$ spin density distribution, where the spin density was found to be well distributed over the entire complex, (Fig. 7). The photophysical properties of $1\left(\lambda_{\mathrm{PL}}=\right.$ $\left.515 \mathrm{~nm}, \Phi_{\mathrm{PL}}=81 \%\right)$ are remarkably similar to $\mathbf{R} 1\left(\lambda_{\mathrm{PL}}=\right.$ $\left.515 \mathrm{~nm}, \Phi_{\mathrm{PL}}=72 \%\right)$ and $\mathbf{R} 3\left(\lambda_{\mathrm{PL}}=517 \mathrm{~nm}, \Phi_{\mathrm{PL}}=53 \%\right)$, suggesting that the additional nitrogen in the pyrimidyl ring in this instance does not have a significant influence on the energy of the $T_{1}$ state.

By contrast, 2 displays structured ${ }^{3} \mathrm{LC}$ emission localized on the $\mathrm{C}^{\wedge} \mathrm{N}$ ligands, that is significantly blue-shifted $\left(\lambda_{\mathrm{PL}}=454,481 \mathrm{~nm}\right.$, $\Phi_{\mathrm{PL}}=77 \%$ ) compared to 1 . The ${ }^{3} \mathrm{LC}$ nature of the emission is further supported by the predicted spin-density distribution. Analogously, complex R2 is blue-shifted $\left(\lambda_{\mathrm{PL}}=470 \mathrm{~nm}, \Phi_{\mathrm{PL}}=68 \%\right)$ compared to complex R1, demonstrating that the $-\mathrm{CF}_{3}$ group exerts a significant blue-shifting effect on the emission energy. However, the blue-shifted emission of $\mathbf{2}$ compared to $\mathbf{R} \mathbf{2}$ implies a synergistic blue-shifting effect between the $-\mathrm{CF}_{3}$ moiety and the pyrimidine compared to the $\mathrm{dFCF}_{3}$ ppy ligand.

While complex 1 showed emission from a mixed ${ }^{3} \mathrm{MLCT} /{ }^{3} \mathrm{LLCT}$ state, the use of the $o$-Xylbiim ligand in 3 and $\mathbf{4}$ renders the $\mathrm{N}^{\wedge} \mathrm{N}$

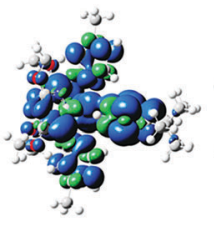

$[1]^{+}$

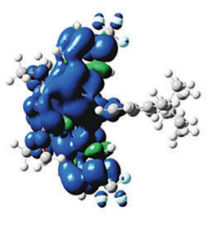

$[2]^{+}$

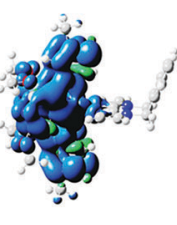

$[3]^{+}$

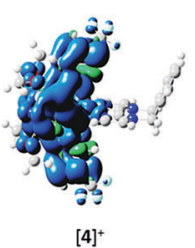

$[4]^{+}$
Fig. 7 Triplet spin density distributions of complexes $\mathbf{1 - 4}$, obtained from TD-DFT [UB3LYP/SBKJC-VDZ for Ir(III) and 6-31G** for C, H, N, O, and F] with $\mathrm{CPCM}(\mathrm{MeCN})$. Contours at an isovalue of 0.02 .

ligand non-chromophoric and thus the emission of 3 originates from a blue-shifted, highly vibronic ${ }^{3} \mathrm{LC}$ state $\left(\lambda_{\mathrm{PL}}=446,475\right.$, $510 \mathrm{~nm}, \Phi_{\mathrm{PL}}=80 \%$ ). These ${ }^{3} \mathrm{LC}$ assignments are corroborated by the $\mathrm{C}^{\wedge} \mathrm{N}$-localised spin density distributions (Fig. 7). The principal vibronic bands in 3 virtually coincide with those of complex 2 , but the relative intensities differ; for complex 3 , the most intense band is at $475 \mathrm{~nm}$, while the band at $446 \mathrm{~nm}$ appears as a less intense shoulder. In the case of 2 , the emission intensities of both bands are very similar, with the band at $454 \mathrm{~nm}$ being only marginally more intense than that at $481 \mathrm{~nm}$. Finally, complex 3 has a third shoulder at $510 \mathrm{~nm}$ that is almost totally suppressed in the case of 2. Thus, $\mathbf{2}$ appears bluer than $\mathbf{3}$ due to a smaller contribution to the emission from the blue-green region of the spectrum. The blueshift in emission observed for $\mathbf{3}$ compared with $\mathbf{1}$ is not mirrored in the analogous comparison between $\mathbf{4}$ and 2. In this instance, the emission profile of $4\left(\lambda_{\mathrm{PL}}=457,483 \mathrm{~nm}, \Phi_{\mathrm{PL}}=73 \%\right)$, overlaps almost coincidentally with 2 , albeit with a small redshift in the former. It is therefore apparent that when the $-\mathrm{CF}_{3}$ group is incorporated into the $\mathrm{C}^{\wedge} \mathrm{N}$ ligand, the emission becomes totally localised on the cyclometalating ligand and the ancillary ligand exerts almost no influence.

The relatively long excited state lifetimes $(>4 \mu \mathrm{s})$ and small radiative constants $k_{\mathrm{r}}\left(<2 \times 10^{5} \mathrm{~s}^{-1}\right)$ further support the predominant ${ }^{3} \mathrm{LC}$ character of the emissive triplet state in complexes 2-4. By contrast, complex 1 displays a shorter $\tau_{\mathrm{e}}$ $(1.36 \mu \mathrm{s})$ and a larger $k_{\mathrm{r}}\left(5.96 \times 10^{5} \mathrm{~s}^{-1}\right)$, which is in line with the ${ }^{3}$ CT-based triplet excited state. The optoelectronic properties of complex 2 are therefore remarkable: although the LUMO of the complex resides on the $\mathrm{N}^{\wedge} \mathrm{N}$ ligand (see electrochemistry section), which is expected to result in a $\mathrm{d} \pi-\pi^{*}{ }_{\mathrm{N} \wedge \mathrm{N}}$ MLCT/LLCT

Table 4 Relevant solution state and thin film photophysical data for complexes $1-4^{a}$

\begin{tabular}{|c|c|c|c|c|c|c|c|c|}
\hline \multicolumn{7}{|l|}{ Solution } & \multicolumn{2}{|l|}{ Thin film } \\
\hline Complex & $\lambda_{\mathrm{em}}(\mathrm{nm})^{b, c}$ & $\operatorname{CIE}(x, y)$ & $\Phi_{\mathrm{PL}}^{d}(\%)$ & $\tau_{\mathrm{e}}^{e}(\mu \mathrm{s})$ & $k_{\mathrm{r}} \times 10^{5} \mathrm{~s}^{-1}$ & $k_{\mathrm{nr}} \times 10^{5} \mathrm{~s}^{-1}$ & $\lambda_{\mathrm{em}}^{f, g}(\mathrm{~nm})$ & $\Phi_{\mathrm{PL}}^{f, g}(\%)$ \\
\hline 1 & 515 & $0.20,0.41$ & 81 & 1.36 & 5.96 & 1.40 & 500 & 65 \\
\hline 3 & 446 (0.69), 475 (1.00), $510(0.83)$ & $0.16,0.23$ & 80 & 9.01 & 0.89 & 0.22 & $451(0.66), 481(1.00), 513(0.82)$ & 15 \\
\hline 4 & $457(1.00), 483(0.96)$ & $0.15,0.23$ & 73 & 4.77 & 1.53 & 0.57 & $486(0.95), 512(1.00)$ & 9 \\
\hline R1 & 515 & - & 72 & 1.36 & 5.29 & 2.06 & & \\
\hline $\mathbf{R} 2$ & 470 & - & 68 & 2.30 & 2.96 & 1.39 & & \\
\hline
\end{tabular}

${ }^{a}$ Measurements at $298 \mathrm{~K}$ in deaerated MeCN. ${ }^{b} \lambda_{\text {exc }}: 360 \mathrm{~nm} .{ }^{c}$ Numbers in brackets denote relative weightings for each emission band. ${ }^{d}$ Quinine sulfate used as the reference $\left(\Phi_{\mathrm{PL}}=54.6 \%\right.$ in $0.5 \mathrm{M} \mathrm{H}_{2} \mathrm{SO}_{4}$ at $\left.298 \mathrm{~K}\right){ }^{28}{ }^{e} \lambda_{\text {exc }}: 375 \mathrm{~nm} .{ }^{f}$ Thin film composition: complex:1-butyl-3methylimidazolium hexafluorophosphate $4: 1$ molar ratio. ${ }^{g} \lambda_{\text {exc }}: 320 \mathrm{~nm}$. 
state of lower energy than the $\pi_{\mathrm{C}^{\wedge} \mathrm{N}^{-}}-\pi^{*}{ }_{\mathrm{C} \wedge \mathrm{N}}$ LC state, emission appears instead to originate from the higher energy LC state.

We can take this into consideration further if we consider the comparison of $\mathbf{1}$ with R1. Photophysically, these complexes are almost indistinct with both exhibiting green emission from the ${ }^{3} \mathrm{MLCT} /{ }^{3}$ LLCT state and showing similar excited state lifetime and photoluminescence quantum yields. We can therefore conclude that in this instance the optoelectronic properties exerted by the Mepypyrm $\mathrm{C}^{\wedge} \mathrm{N}$ ligand on complex 1 compared to the dFppy $\mathrm{C}^{\wedge} \mathrm{N}$ ligand on complex $\mathbf{R} \mathbf{1}$ are essentially the same. By contrast, the analogous comparison of the photophysical properties does not hold between complexes 2 (containing the $\mathrm{CF}_{3}$ pypyrm $\mathrm{C}^{\wedge} \mathrm{N}$ ligand) and $\mathbf{R} 2$ (containing the $\mathrm{dFCF}_{3}$ ppy $\mathrm{C}^{\wedge} \mathrm{N}$ ligand). Complex $\mathbf{R} 2$ is blue-shifted compared to $\mathbf{R} \mathbf{1}$ but nevertheless emits from the predominant ${ }^{3} \mathrm{LLCT} /{ }^{3} \mathrm{MLCT}$ state implicating a chromophoric contribution from the dtBubpy $\mathrm{N}^{\wedge} \mathrm{N}$ ligand. The $\mathrm{CF}_{3}$ pypyrm $\mathrm{C}^{\wedge} \mathrm{N}$ ligand, on the other hand, renders the dtBubpy ancillary ligand in complex 2 non-chromophoric, which is highly unusual for iridium(III) complexes bearing dtBubpy $\mathrm{N}^{\wedge} \mathrm{N}$ ligands.

This unusual feature of the $\mathrm{CF}_{3}$ pypyrm $\mathrm{C}^{\wedge} \mathrm{N}$ ligand is mirrored in complex $\mathbf{4}$, which has virtually identical photophysical properties to complex 2 (similar emission maximum, profile, $\Phi_{\mathrm{PL}}, \tau_{\mathrm{e}}$ ) despite the presence of the $o$-Xylbiim ancillary ligand that has a much higher energy LUMO compared to dtBubpy (see the more negative reduction potential of 4 compared to 2 ). The reasons behind such unexpected behaviour are currently not understood but are most likely due to uncommon branching of events at very short time scales (ns and below), which is beyond the scope of this manuscript.

The highest energy emission maxima, $E_{0-0}$, are blue-shifted and in the order $3\left(22421 \mathrm{~cm}^{-1}, 446 \mathrm{~nm}\right)>2\left(22026 \mathrm{~cm}^{-1}\right.$, $454 \mathrm{~nm}) \sim 4\left(21882 \mathrm{~cm}^{-1}, 457 \mathrm{~nm}\right)>1\left(19417 \mathrm{~cm}^{-1}, 515 \mathrm{~nm}\right)$ (Table 4). The predicted emission maxima, $E_{\mathrm{AE}}=E\left(\mathrm{~T}_{1}\right)-E\left(\mathrm{~S}_{0}\right)$ at the $\mathrm{T}_{1}$ optimized geometry (adiabatic electronic emission) obtained by DFT calculations for 1-4 are, respectively, at 482, 441, 422 and $440 \mathrm{~nm}$. These values match closely with those observed experimentally with relative errors of $6.8 \%, 6.0 \%$, 9.1\% and 6.8\%, respectively for complexes 1-4. Crucially, these calculations predict essentially no change in emission energy between complexes 2 and 4 , corroborating the feature observed for these complexes in solution. This overall trend is generally mimicked by the measurements pertaining to the ground state, with a gradually increasing HOMO-LUMO gap across the series calculated from the electrochemistry data $\left[\Delta E_{\text {redox }}: 3(3.46 \mathrm{~V})>\right.$ $\mathbf{4}(3.39 \mathrm{~V})>\mathbf{2}(3.08 \mathrm{~V})>\mathbf{1}(2.92 \mathrm{~V})]$ and the DFT calculations $\left[\left|E_{\text {Luмо-номо }}\right|: 3(4.26 \mathrm{eV})>\mathbf{4}(4.12 \mathrm{eV})>2(3.77 \mathrm{eV})>\mathbf{1}\right.$ $(3.60 \mathrm{eV})]$ (Table 2). However, these values also predict a much larger energy difference between complexes $\mathbf{2}$ and $\mathbf{4}$, which is not observed in the PL spectrum or predicted by the $T_{1}$ spin density DFT calculations. This highlights the difference in excited state $v s$. ground sate measurements, as well as reflects the unusual photophysical features of the $\mathrm{CF}_{3}$ pypyrm $\mathrm{C}^{\wedge} \mathrm{N}$ ligand in the excited state.

Complex $\mathbf{R 4}$ is the bluest among the reference complexes $\left(\lambda_{\mathrm{PL}}=459,487 \mathrm{~nm}, \Phi_{\mathrm{PL}}=90 \%\right)$ due to the adoption of the

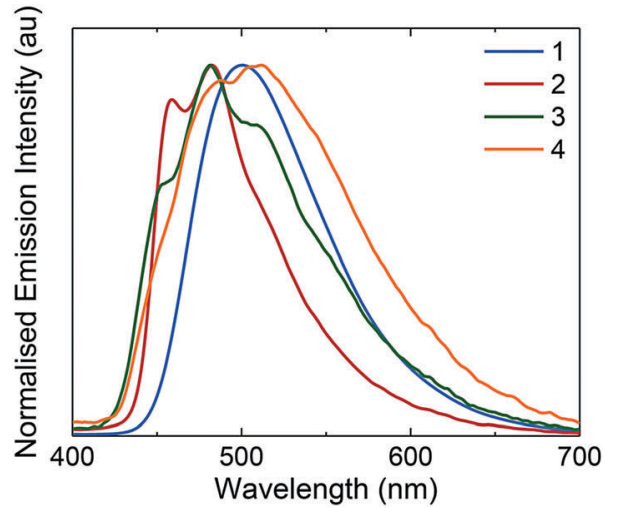

Fig. 8 Neat thin-film photoluminescence spectra for $1-4\left(\lambda_{\text {exc }}=320 \mathrm{~nm}\right)$.

$o$-Xylbiim ligand as the $\mathrm{N}^{\wedge} \mathrm{N}$ ligand. Although it is moderately more emissive, complexes $\mathbf{2}$ and $\mathbf{4}$ are modestly blue-shifted in emission, showing that it is possible to achieve significantly blue-shifted emission without employing $\mathrm{C}-\mathrm{F}_{\text {aryl }}$ bonds.

The complexes were also evaluated in light-emitting electrochemical cells (LEECs). In this application the complexes are processed into amorphous thin films. In order to understand the photoluminescence properties in an analogous environment, samples of 1-4 were fabricated by depositing the complexes onto quartz substrates following the same composition and coating conditions as were used for LEEC preparation. The neat thin-film photoluminescence spectra for each complex 1-4 are displayed in Fig. 8. All four emitters preserve the same spectral shape as observed in acetonitrile solution, although the peak position is shifted for $\mathbf{1}$ and 4 . The emission maximum of $\mathbf{1}$ is centred at $500 \mathrm{~nm}$, slightly blue-shifted from what is observed in MeCN. The structured emission profiles of 2 and 3 are essentially identical ( $\lambda_{\max }=458$ and $482 \mathrm{~nm}$ for 2 and 451 , 481 and $513 \mathrm{~nm}$ for 3) to those measured in MeCN. The photoluminescence of $\mathbf{4}$ on the other hand is modestly redshifted compared to that in solution $\left(\lambda_{\max }=486\right.$ and $\left.512 \mathrm{~nm}\right)$. Due to the fact that the photoluminescence spectra are comparable between solution and thin film, it is not unexpected that 1 $\left({ }^{3} \mathrm{MLCT} /{ }^{3} \mathrm{LLCT}\right)$ has the highest emission quantum yield in a thin film $\left(\Phi_{\mathrm{PL}}=65 \%\right)$ while 2,3 and $4\left({ }^{3} \mathrm{LC}\right)$ show lower $\Phi_{\mathrm{PL}}$ values in a thin film $\left(\Phi_{\mathrm{PL}}<20 \%\right)$.

\section{Device characterization}

The electroluminescence properties of 1-4 were evaluated by preparing LEECs with a sandwich architecture, as illustrated in Fig. 9d. The devices were fabricated on an ITO-patterned, cleaned glass substrate, where first a poly(3,4-ethylenedioxythiophene): poly(styrenesulfonate) (PEDOT:PSS) layer was deposited by spincoating. The LEEC active layer was deposited from an acetonitrile solution, which consisted of the emitter mixed with the ionic liquid (IL) 1-butyl-3-methylimidazolium hexafluorophosphate, [Bmim] $\left[\mathrm{PF}_{6}\right]$, in a 4:1 molar ratio (complex: IL). After deposition of the active layer, aluminium was thermally evaporated as the top electrode.

For simplicity, the LEECs containing complexes 1-4 are referred to as L1-L4. The devices were characterized under an 

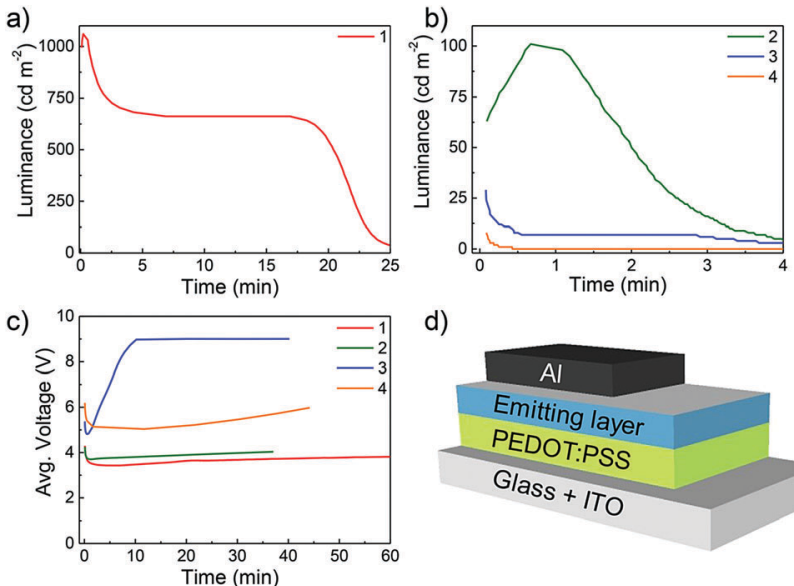

d)

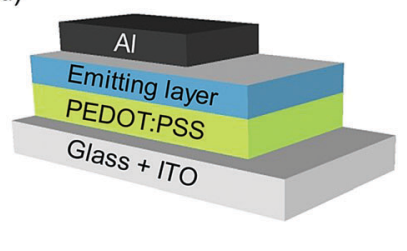

Fig. 9 Time-dependence luminance under average pulsed current driving of $100 \mathrm{~A} \mathrm{~m}^{-2}$ for: (a) LEEC 1 and (b) LEEC 2, 3 and 4; (c) evolution of the driving voltage versus time for the LEECs based on complexes 1-4; (d) schematic of the LEEC architecture.

inert atmosphere by applying a pulsed current $(1 \mathrm{kHz}, 50 \%$ duty cycle). The resulting applied average current density was $100 \mathrm{~A} \mathrm{~m}^{-2}$ due to the duty cycle of $50 \%$. LEECs driven by this operational mode typically show instantaneous luminance, while the voltage needed to maintain the applied current drops rapidly over time to reach a minimum value. This behaviour is explained by taking into account the presence of ions, which dissociate and move towards the electrodes, forming an electric double layer thereby reducing the injection barrier and finally contributing to the formation of $\mathrm{p}$ and $\mathrm{n}$ electrochemically doped regions within the emitting layer. The luminance and

voltage versus time is depicted in Fig. 9 and key parameters are summarized in Table 5.

All LEECs exhibit instantaneous luminance, although with different coloured emissions (Fig. 10). While initially L1, L3 and L4 exhibit blue-green emission, L2 emits sky-blue light. The electroluminescence of $\mathbf{L 1}, \mathbf{L 3}$ and $\mathbf{L} 4$ consists of two peaks centred at 492 and $521 \mathrm{~nm}$ for $\mathbf{L 1}, 486$ and $553 \mathrm{~nm}$ for L3, and 492 and $549 \mathrm{~nm}$ for L4. However, L2 presents a maximum at $485 \mathrm{~nm}$ with a shoulder at $535 \mathrm{~nm}$, which confirms the observed sky-blue colour (CIE: 0.23, 0.39). Nevertheless, this value is among the bluest iTMC LEECs reported employing ionic liquids, with the bluest being only moderately bluer (CIE: $0.20,0.34$ ) than our own. ${ }^{29}$

In the case of $\mathbf{L} \mathbf{1}$ and $\mathbf{L} 2$, the luminance initially rises during the first 12 and 40 seconds, respectively, and then decreases. In the case of $\mathbf{L} \mathbf{3}$ and $\mathbf{L} \mathbf{4}$ the luminance initially drops. The device performance of L1-L4 is typically dependent on the electrochemical and thin film photophysical properties discussed above. On the one hand, the voltage applied to $\mathbf{L 1}$ and $\mathbf{L 2}$ remains constant once efficient charge injection is achieved ( $\sim 1$ minute to reach the minimum voltage in both cases), which is indicative of an electrochemically stable system. However, for L3 and L4 the voltage increases after 1 and 12 minutes, respectively, clearly demonstrating the instability of these devices, which must be due to the presence of the $o$-Xylbiim ancillary ligand and its irreversible electrochemistry upon reduction. This behaviour could be related to the chemical degradation of the active material leading to an increase in the layer resistance. The observed device efficiencies follow trends observed in the thinfilm photoluminescence quantum yield, with L1 (complex 1 has a $\Phi_{\mathrm{PL}}=65 \%$ ) a bright and efficient device with a maximum

Table 5 Performance of EL devices prepared with complexes 1-4

\begin{tabular}{|c|c|c|c|c|c|c|c|c|}
\hline Device & $\operatorname{Lum}_{\max }{ }^{a}\left(\mathrm{~cd} \mathrm{~m}{ }^{-2}\right)$ & $t_{50 \mathrm{~cd}}^{b}(\mathrm{~s})$ & $t_{1 / 2}^{c}(\min )$ & Efficacy $_{\max }{ }^{d}\left(\mathrm{~cd} \mathrm{~A} \mathrm{~A}^{-1}\right)$ & $\mathrm{PE}_{\max }^{e}\left(\operatorname{lm~W}{ }^{-1}\right)$ & $\mathrm{EQE}_{\max }{ }^{f}(\%)$ & $\lambda_{\mathrm{EL}}^{g}(\mathrm{~nm})$ & $\operatorname{CIE}^{h}(x, y)$ \\
\hline $\mathbf{L 1}$ & 1060 & $<5$ & 20 & 10.5 & 4.6 & 3.8 & 492,521 & $0.34,0.49$ \\
\hline $\mathbf{L} 2$ & 101 & $<5$ & 2 & 1.0 & 0.4 & 0.4 & 485,535 (sh) & $0.23,0.39$ \\
\hline L3 & 29 & - & 0.2 & 0.3 & $<0.1$ & 0.1 & 486,553 & $0.31,0.45$ \\
\hline L4 & 8 & - & 0.1 & $<0.1$ & $<0.1$ & $<0.1$ & 492(sh), 549 & $0.32,0.48$ \\
\hline 01 & 72 & - & - & 5.7 & 5.3 & 2.1 & 490,554 & $0.34,0.46$ \\
\hline
\end{tabular}

${ }^{a}$ Maximum luminance. ${ }^{b}$ Time to reach $50 \mathrm{~cd} \mathrm{~m}^{-2} .{ }^{c}$ Time to reach one-half of the maximum luminance. ${ }^{d}$ Maximum efficacy. ${ }^{e}$ Maximum power efficiency. ${ }^{f}$ Maximum external quantum efficiency. ${ }^{g}$ Emission maximum in electroluminescence. ${ }^{h}$ CIE coordinates obtained from the electroluminescence spectrum at the beginning of operation.

a)

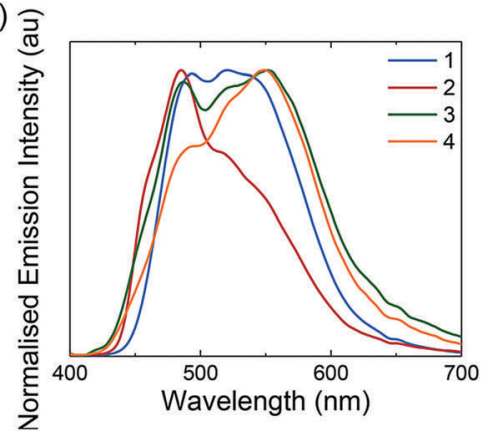

b)
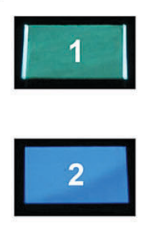

3 c)

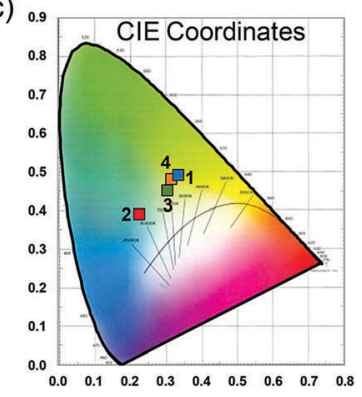

Fig. 10 (a) Normalised electroluminescence spectra for L1-L4. (b) Photographs of L1-L3 under operation. (c) CIE coordinate chart. 

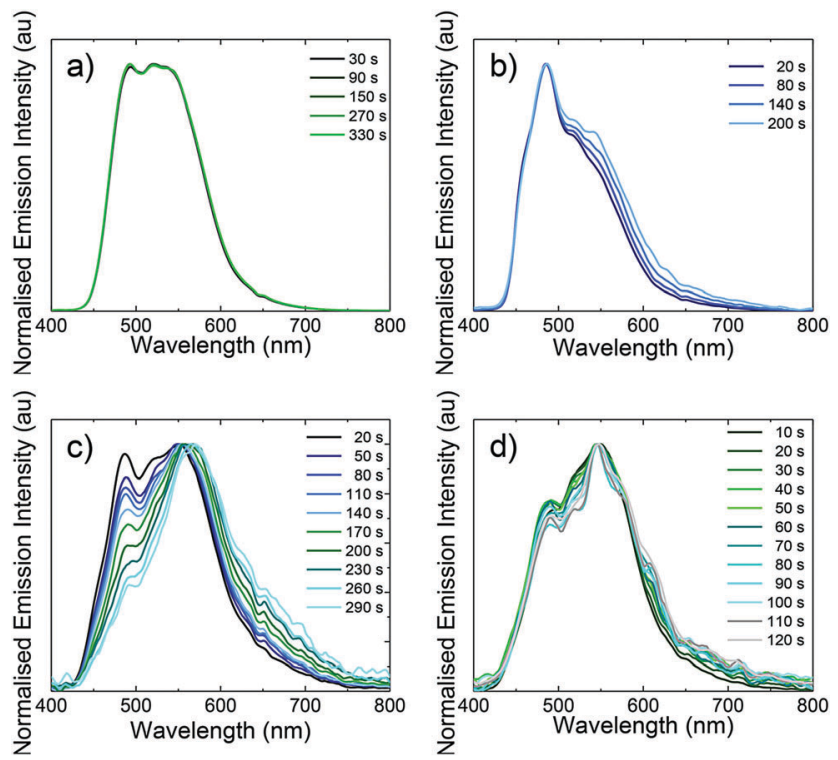

Fig. 11 Normalised electroluminescence spectra versus time for (a) L1 (b) L2; (c) L3; and (d) L4.

luminance of $1060 \mathrm{~cd} \mathrm{~m}^{-2}$ and $10.5 \mathrm{~cd} \mathrm{~A}^{-1}$. Device $\mathbf{L} 2$ (complex 2 has $\Phi_{\mathrm{PL}}=17 \%$ ) shows moderately blue emissive efficiency,

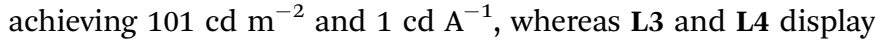
lower luminance values than $40 \mathrm{~cd} \mathrm{~m}^{-2}\left(0.3 \mathrm{~cd} \mathrm{~A}^{-1}\right)$ due to their lower thin-film $\Phi_{\mathrm{PL}}$ values.

As previously reported for other blue-green LEECs, ${ }^{10 b, 16 a, 30}$ the device lifetimes presented here are not very long (in the range of 8 seconds to 20 minutes). In general, the colour stability of bluegreen LEECs is rarely described. In 2013, Meier et al. reported an example of a blue-emitting iridium complex that suffers a red shift of the electroluminescence, which led to a blue-greenish emission during the LEEC operation. Hence, the importance of studying the colour stability during the electroluminescence operation in blue-green emitters is of particular interest. ${ }^{10 a}$ Although the origin of this behaviour is unclear, one hypothesis is that the degradation of the emitter is the main reason. To verify whether emitter degradation is the cause of poor device lifetime in L1-L4, the electroluminescence spectra of the four LEECs versus operation time was investigated (Fig. 11). With the exception of L3, the colour emission remains reasonably stable throughout the operation of the device. The fact that $\mathbf{L 3}$ is colour unstable is also supported by the steeper voltage increase observed during the LEEC operation (Fig. 9c), likely due to the chemical degradation of the complex. The stable sky-blue electroluminescence of $\mathbf{L 2}$ is of particular interest because this LEEC shows good colour quality and stability with comparable performance to blue LEECs. ${ }^{1 a, 3 b}$ Hence, these experiments appear to identify for the first time that the decrease in light emission in these LEECs is not related to the direct emitter degradation, implying that the emitters located in the non-doped light-emitting zone of the device are unaffected. It is still possible that the emitters in the doped zones (where they are oxidized or reduced) do react and degrade. Further studies on emission angle-dependent experiments are needed to try and identify the emission zone in the thin film and to see if these zones move over time.

In general, many blue-green LEECs are reported to exhibit poor performance, probably due to exciton-exciton quenching. ${ }^{31}$ An attempt to improve the device efficiency was explored by integrating the most highly emissive complex, $\mathbf{1}$, in an OLED architecture. The device was prepared by sequential deposition of a $30 \mathrm{~nm}$ PEDOT:PSS layer as the hole injection layer (HIL), $35 \mathrm{~nm}$ of $N 4, N 4^{\prime}$ di(naphthalen-1-yl)-N4,N4'-bis(4-vinylphenyl)biphenyl-4,4'-diamine a)

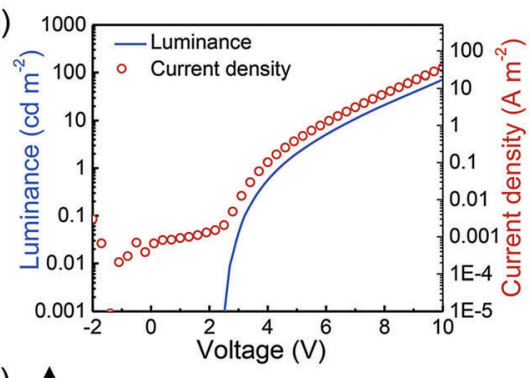

c)

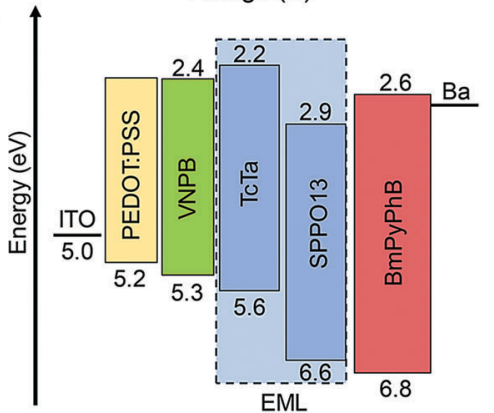

b)

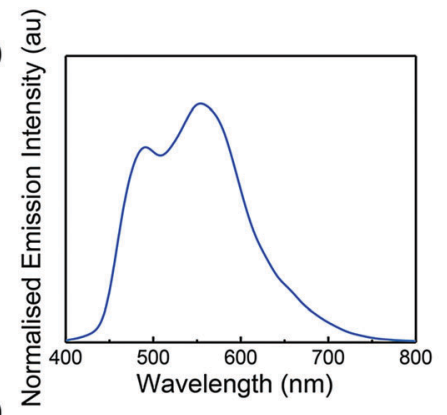

d)

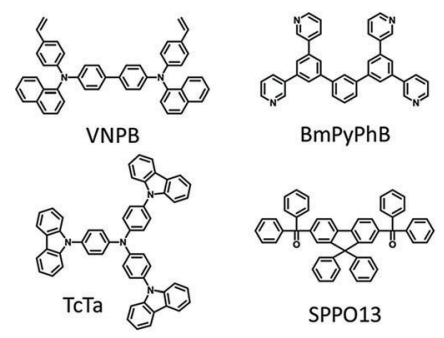

Fig. 12 Luminance (solid blue line) and current density (red dotted line) versus voltage for the OLED containing 1 (a); its normalised electroluminescence spectra (b); the device architecture and the corresponding energy level diagram (c); the chemical structure of the components used for the OLED preparation (d). 
(VNPB) as the hole transport layer (HTL), a $30 \mathrm{~nm}$ emissive layer (EML), $40 \mathrm{~nm}$ of 1,3-bis[3,5-di(pyridin-3-yl)phenyl]benzene (BmPyPhB) as an electron transport material (ETM) and barium (5 $\mathrm{nm})$-silver $(70 \mathrm{~nm})$ as the cathode. The HIL was coated in air whereas the HTL and EML were coated under an inert atmosphere. Before the emissive layer coating, the HTL was thermally treated in order to make the VNPB resistant to toluene. ${ }^{32}$ The emissive layer was deposited from a $10 \mathrm{mg} \mathrm{mL}^{-1}$ anisole solution, which consists of a mixture of 4,4',4"-tris(carbazol-9-yl)triphenylamine (TcTa), 2,7-bis(diphenylphosphoryl)-9,9'-spirobifluorene (SPPO13) and complex 1. The concentration of 1 was 10 wt $\%$ with respect to solids. The OLED, O1, was characterized by a voltage scan and by simultaneously measuring the luminance and current ( $I-V-L$ curve) and their characteristics are depicted in Fig. 12. The OLED showed a greener electroluminescence (CIE: 0.34, 0.46) than the corresponding LEEC L1 $(0.34,0.49)$, as the peak at $490 \mathrm{~nm}$ had lower intensity than the peak at $554 \mathrm{~nm}$. The turn-on voltage for both current and luminance was at approximately $2.4-2.5 \mathrm{~V}$, indicating balanced carriers in the device. The power efficiency was slightly improved $\left(5.3 \mathrm{~lm} \mathrm{~W}^{-1}\right)$, although the efficacy (5.7 cd $\mathrm{A}^{-1}$ ) is lower compared to $\mathbf{L 1}$ (10.5 cd $\mathrm{A}^{-1}$ ). Hence, this lower efficacy should be not related to the exciton-exciton quenching but more related to the different device architecture in $\mathbf{0 1}$.

\section{Conclusions}

The first examples of cationic iridium(III) complexes bearing cyclometalating pyrimidine rings are reported. Combining electronwithdrawing pyrimidyl nitrogen atoms with ambivalent methoxy substituents gives $\mathrm{C}^{\wedge} \mathrm{N}$ ligands with blue-shifted emission properties comparable to fluorinated $\mathrm{C}^{\wedge} \mathrm{N}$ ligands such as $\mathrm{dFppy}$. The four complexes are the bluest cationic iridium(III) complexes reported to date $\left(\lambda_{\mathrm{PL}}=464-515 \mathrm{~nm} ; \Phi_{\mathrm{PL}}=73-81 \%\right.$ in MeCN solution) that do not contain $\mathrm{sp}^{2}$ carbon-fluorine bonds. In particular, complexes 2 and 4 , bearing the more electrochemically resilient $-\mathrm{CF}_{3}$ group on the pyridine moiety of the $\mathrm{C}^{\wedge} \mathrm{N}$ ligands exhibit ligand-centred emission that is independent of the nature of the $\mathrm{N}^{\wedge} \mathrm{N}$ ligand completing the coordination sphere. To that end, complex 2 is particularly remarkable as it is a rare example of a complex bearing a non-chromophoric dtBubpy ancillary ligand. In LEECs, the emitters show stabilities $\left(t_{1 / 2}=0.1-20 \mathrm{~min}\right)$ and efficiencies (EQE $=0.1-3.8 \%$ ) similar to the previously reported LEECs employing $\mathrm{sp}^{2}$-fluorinated iridium(III) complexes. However, the unique and remarkable colour stability of these emitters in the device, even as the devices die, has allowed us to show for the first time that emitter degradation in the non-doped light-emitting zone is not an implicating factor in the stability of LEEC devices. Further studies pertaining to the chemical integrity of the emitters localised at the electrode interfaces are ongoing to determine if the redox processes in the doped zones contribute to the degradation of these devices.

\section{Conflicts of interest}

There are no conflicts to declare.

\section{Acknowledgements}

The St Andrews team acknowledges the University of St Andrews and the Engineering and Physical Sciences Research Council for financial support (EP/M02105X/1; EP/J500549/1; EP/K503162/1; EP/L505097/1) and Johnson Matthey and Umicore AG for the gift of materials. The Birmingham team acknowledges the European Research Council (HetIridium, CIG-322280). We thank the EPSRC UK National Mass Spectrometry Facility at Swansea University for analytical services. The Valencian team acknowledges the financial support from the Spanish Ministry of Economy and Competitiveness (MINECO) via the Unidad de Excelencia María de Maeztu MDM-2015-0538 and MAT201455200, PCIN-2015-255 and CTQ2015-71154-P and the Generalitat Valenciana (PROMETEO/2016/135). C. M. thanks MINECO for her predoctoral contract.

\section{References}

1 (a) A. F. Henwood and E. Zysman-Colman, Top. Curr. Chem., 2016, 374, 36; (b) S. Tang and L. Edman, Top. Curr. Chem., 2016, 374, 40; (c) T. Hu, L. He, L. Duan and Y. Qiu, J. Mater. Chem., 2012, 22, 4206-4215; (d) R. D. Costa, E. Ortí, H. J. Bolink, F. Monti, G. Accorsi and N. Armaroli, Angew. Chem., Int. Ed., 2012, 51, 8178-8211.

2 Q. Pei, G. Yu, C. Zhang, Y. Yang and A. J. Heeger, Science, 1995, 269, 1086-1088.

3 (a) A. F. Henwood and E. Zysman-Colman, Chem. Commun., 2017, 53, 807-826; (b) D. Ma, T. Tsuboi, Y. Qiu and L. Duan, Adv. Mater., 2017, 29, 1603253; (c) P. Li, Q.-Y. Zeng, H.-Z. Sun, M. Akhtar, G.-G. Shan, X.-G. Hou, F.-S. Li and Z.-M. Su, J. Mater. Chem. C, 2016, 4, 10464-10470; (d) Q. Zeng, F. Li, T. Guo, G. Shan and Z. Su, Sci. Rep., 2016, 6, 27613.

4 (a) A. J. Bader, A. A. Ilkevich, I. V. Kosilkin and J. M. Leger, Nano Lett., 2011, 11, 461-465; (b) G. Qian, Y. Lin, G. Wantz, A. R. Davis, K. R. Carter and J. J. Watkins, Adv. Funct. Mater., 2014, 24, 4484-4490.

5 (a) M. F. Aygüler, M. D. Weber, B. M. D. Puscher, D. D. Medina, P. Docampo and R. D. Costa, J. Phys. Chem. C, 2015, 119, 12047-12054; (b) H. Zhang, H. Lin, C. Liang, H. Liu, J. Liang, Y. Zhao, W. Zhang, M. Sun, W. Xiao, H. Li, S. Polizzi, D. Li, F. Zhang, Z. He and W. C. H. Choy, Adv. Funct. Mater., 2015, 25, 7226-7232.

6 S. van Reenen, P. Matyba, A. Dzwilewski, R. A. J. Janssen, L. Edman and M. Kemerink, J. Am. Chem. Soc., 2010, 132, 13776-13781.

7 (a) A. Asadpoordarvish, A. Sandström, C. Larsen, R. Bollström, M. Toivakka, R. Österbacka and L. Edman, Adv. Funct. Mater., 2015, 25, 3238-3245; (b) A. Sandström, A. Asadpoordarvish, J. Enevold and L. Edman, Adv. Mater., 2014, 26, 4975-4980.

8 L. He, L. Duan, J. Qiao, R. Wang, P. Wei, L. Wang and Y. Qiu, Adv. Funct. Mater., 2008, 18, 2123-2131.

9 X. Yang, X. Xu and G. Zhou, J. Mater. Chem. C, 2015, 3, 913-944.

10 (a) S. B. Meier, W. Sarfert, J. M. Junquera-Hernández, M. Delgado, D. Tordera, E. Ortí, H. J. Bolink, F. Kessler, 
R. Scopelliti, M. Grätzel, M. K. Nazeeruddin and E. Baranoff, J. Mater. Chem. C, 2013, 1, 58-68; (b) L. He, L. Duan, J. Qiao, G. Dong, L. Wang and Y. Qiu, Chem. Mater., 2010, 22, 3535-3542. For representative of white-emitting LEECs see: (c) L. He, J. Qiao, L. Duan, G. Dong, D. Zhang, L. Wang and Y. Qiu, Adv. Funct. Mater., 2009, 19, 2950-2960; (d) A. B. Tamayo, S. Garon, T. Sajoto, P. I. Djurovich, I. M. Tsyba, R. Bau and M. E. Thompson, Inorg. Chem., 2005, 44, 8723-8732.

11 H.-B. Wu, H.-F. Chen, C.-T. Liao, H.-C. Su and K.-T. Wong, Org. Electron., 2012, 13, 483-490.

12 (a) H. J. Bolink, E. Coronado, R. D. Costa, P. Gavina, E. Ortí and S. Tatay, Inorg. Chem., 2009, 48, 3907-3909; (b) M. S. Lowry and S. Bernhard, Chem. - Eur. J., 2006, 12, 7970-7977; (c) S. Ladouceur and E. Zysman-Colman, Eur. J. Inorg. Chem., 2013, 2985-3007.

13 (a) V. Sivasubramaniam, F. Brodkorb, S. Hanning, H. P. Loebl, V. van Elsbergen, H. Boerner, U. Scherf and M. Kreyenschmidt, J. Fluorine Chem., 2009, 130, 640-649; (b) Y. Zheng, A. S. Batsanov, R. M. Edkins, A. Beeby and M. R. Bryce, Inorg. Chem., 2012, 51, 290-297; (c) D. Tordera, J. J. Serrano-Pérez, A. Pertegás, E. Ortí, H. J. Bolink, E. Baranoff, M. K. Nazeeruddin and J. Frey, Chem. Mater., 2013, 25, 3391-3397.

14 M. L. P. Reddy and K. S. Bejoymohandas, J. Photochem. Photobiol., C, 2016, 29, 29-47.

15 (a) J. Frey, B. F. E. Curchod, R. Scopelliti, I. Tavernelli, U. Rothlisberger, M. K. Nazeeruddin and E. Baranoff, Dalton Trans., 2014, 43, 5667-5679; (b) C. Hansch, A. Leo and R. W. Taft, Chem. Rev., 1991, 91, 165-195.

16 (a) S. Evariste, M. Sandroni, T. W. Rees, C. Roldan-Carmona, L. Gil-Escrig, H. J. Bolink, E. Baranoff and E. ZysmanColman, J. Mater. Chem. C, 2014, 2, 5793-5804; (b) H. Oh, K.-M. Park, H. Hwang, S. Oh, J. H. Lee, J.-S. Lu, S. Wang and Y. Kang, Organometallics, 2013, 32, 6427-6436; (c) J. Lee, H. Oh, J. Kim, K.-M. Park, K. S. Yook, J. Y. Lee and Y. Kang, J. Mater. Chem. C, 2014, 2, 6040.

17 (a) B. J. Coe, M. Helliwell, J. Raftery, S. Sanchez, M. K. Peers and N. S. Scrutton, Dalton Trans., 2015, 44, 20392-20405; (b) B. J. Coe, M. Helliwell, S. Sanchez, M. K. Peers and N. S. Scrutton, Dalton Trans., 2015, 44, 15420-15423.

18 (a) Y.-T. Chang, J.-K. Chang, Y.-T. Lee, P.-S. Wang, J.-L. Wu, C.-C. Hsu, I. W. Wu, W.-H. Tseng, T.-W. Pi, C.-T. Chen and C.-I. Wu, ACS Appl. Mater. Interfaces, 2013, 5, 10614-10622; (b) T. Duan, T.-K. Chang, Y. Chi, J.-Y. Wang, Z.-N. Chen, W.-Y. Hung, C.-H. Chen and G.-H. Lee, Dalton Trans., 2015, 44, 14613-14624; (c) Q.-L. Xu, X. Liang, L. Jiang, Y. Zhao and Y.-X. Zheng, Dalton Trans., 2016, 45, 7366-7372.

19 (a) A. F. Henwood, S. Evariste, A. M. Z. Slawin and E. Zysman-Colman, Faraday Discuss., 2014, 174, 165-182; (b) A. F. Henwood, A. K. Bansal, D. B. Cordes, A. M. Z. Slawin, I. D. W. Samuel and E. Zysman-Colman, J. Mater. Chem. C, 2016, 4, 3726-3737.

20 (a) D. Rota Martir, A. K. Bansal, V. Di Mascio, D. B. Cordes, A. F. Henwood, A. M. Z. Slawin, P. C. J. Kamer, L. MartinezSarti, A. Pertegas, H. J. Bolink, I. D. W. Samuel and E. Zysman-Colman, Inorg. Chem. Front., 2016, 3, 218-235; (b) V. N. Kozhevnikov, Y. Zheng, M. Clough, H. A. Al-Attar, G. C. Griffiths, K. Abdullah, S. Raisys, V. Jankus, M. R. Bryce and A. P. Monkman, Chem. Mater., 2013, 25, 2352-2358.

21 N. Miyaura, T. Yanagi and A. Suzuki, Synth. Commun., 1981, 11, 513-519.

22 E. Baranoff, B. F. E. Curchod, J. Frey, R. Scopelliti, F. Kessler, I. Tavernelli, U. Rothlisberger, M. Grätzel and M. K. Nazeeruddin, Inorg. Chem., 2011, 51, 215-224.

23 R. D. Costa, E. Ortí, H. J. Bolink, S. Graber, S. Schaffner, M. Neuburger, C. E. Housecroft and E. C. Constable, Adv. Funct. Mater., 2009, 19, 3456-3463.

24 (a) Y.-Y. Lyu, Y. Byun, O. Kwon, E. Han, W. S. Jeon, R. R. Das and K. Char, J. Phys. Chem. B, 2006, 110, 10303-10314; (b) A.-F. Ma, H.-J. Seo, S.-H. Jin, U.-C. Yoon, M.-H. Hyun, S.-K. Kang and Y.-I. Kim, Bull. Korean Chem. Soc., 2009, 30, 2754-2758.

25 M. S. Lowry, J. I. Goldsmith, J. D. Slinker, R. Rohl, R. A. Pascal, G. G. Malliaras and S. Bernhard, Chem. Mater., 2005, 17, 5712-5719.

26 V. V. Pavlishchuk and A. W. Addison, Inorg. Chim. Acta, 2000, 298, 97-102.

27 C. M. Cardona, W. Li, A. E. Kaifer, D. Stockdale and G. C. Bazan, Adv. Mater., 2011, 23, 2367.

28 W. H. Melhuish, J. Phys. Chem., 1961, 65, 229-235.

29 (a) C.-H. Yang, J. Beltran, V. Lemaur, J. Cornil, D. Hartmann, W. Sarfert, R. Fröhlich, C. Bizzarri and L. De Cola, Inorg. Chem., 2010, 49, 9891-9901; (b) A. F. Henwood and E. Zysman-Colman, Iridium(III) in Optoelectronic and Photonics Applications, John Wiley \& Sons, Ltd, 2017, pp. 275-357. 30 (a) D. Tordera, A. M. Bünzli, A. Pertegás, J. M. JunqueraHernández, E. C. Constable, J. A. Zampese, C. E. Housecroft, E. Ortí and H. J. Bolink, Chem. - Eur. J., 2013, 19, 8597-8609; (b) L. He, L. Duan, J. Qiao, D. Zhang, L. Wang and Y. Qiu, Chem. Commun., 2011, 47, 6467-6469; (c) B. Chen, Y. Li, W. Yang, W. Luo and H. Wu, Org. Electron., 2011, 12, 766-773.

31 S. B. Meier, D. Hartmann, D. Tordera, H. J. Bolink, A. Winnacker and W. Sarfert, Phys. Chem. Chem. Phys., 2012, 14, 10886-10890.

32 J. Xu, O. Voznyy, R. Comin, X. Gong, G. Walters, M. Liu, P. Kanjanaboos, X. Lan and E. H. Sargent, Adv. Mater., 2016, 28, 2807-2815. 